\title{
Analysis of a jet stream induced gravity wave associated with an observed stratospheric ice cloud over Greenland
}

\author{
S. Buss ${ }^{1,2}$, A. Hertzog ${ }^{3}$, C. Hostettler ${ }^{4}$, T. P. Bui ${ }^{5}$, D. Lüthi ${ }^{1}$, and H. Wernli ${ }^{1,6}$ \\ ${ }^{1}$ Institute for Atmospheric and Climate Science, ETH Zürich, Switzerland \\ ${ }^{2}$ Swiss Federal Office of Meteorology and Climatology (MeteoSwiss), Zürich, Switzerland \\ ${ }^{3}$ Laboratoire de météorologie dynamique, Palaiseau, France \\ ${ }^{4}$ NASA, Langley Research Center, Hampton VA, USA \\ ${ }^{5}$ NASA Ames Research Center, Moffett Field CA, USA \\ ${ }^{6}$ Institut für Physik der Atmosphäre, Universität Mainz, Germany
}

Received: 23 September 2003 - Published in Atmos. Chem. Phys. Discuss.: 18 November 2003

Revised: 14 June 2004 - Accepted: 10 July 2004 - Published: 3 August 2004

\begin{abstract}
A polar stratospheric ice cloud (PSC type II) was observed by airborne lidar above Greenland on 14 January 2000. It was the unique observation of an ice cloud over Greenland during the SOLVE/THESEO 2000 campaign. Mesoscale simulations with the hydrostatic HRM model are presented which, in contrast to global analyses, are capable to produce a vertically propagating gravity wave that induces the low temperatures at the level of the PSC afforded for the ice formation. The simulated minimum temperature is $\sim 8 \mathrm{~K}$ below the driving analyses and $\sim 4.5 \mathrm{~K}$ below the frost point, exactly coinciding with the location of the observed ice cloud. Despite the high elevations of the Greenland orography the simulated gravity wave is not a mountain wave. Analyses of the horizontal wind divergence, of the background wind profiles, of backward gravity wave ray-tracing trajectories, of HRM experiments with reduced Greenland topography and of several diagnostics near the tropopause level provide evidence that the wave is emitted from an intense, rapidly evolving, anticyclonically curved jet stream. The precise physical process responsible for the wave emission could not be identified definitely, but geostrophic adjustment and shear instability are likely candidates.
\end{abstract}

In order to evaluate the potential frequency of such nonorographic polar stratospheric cloud events, the non-linear balance equation diagnostic is performed for the winter 1999/2000. It indicates that ice-PSCs are only occasionally generated by gravity waves emanating from spontaneous adjustment.

Correspondence to: S. Buss

(sbuss@ largeur.com)

\section{Introduction}

In situations where the large-scale stratospheric temperature is slightly above the thresholds for the existence of NAT (nitric acid trihydrate) or ice, gravity waves can be effective in inducing PSCs. At the surface of PSC particles, heterogeneous chlorine activation might occur. $\mathrm{A} \mathrm{Cl}$ atom can in turn eventually destroy several hundreds stratospheric ozone molecules. Thus, in the last years, mountain gravity waves gained substantial consideration as model studies and observations confer them an important role in stratospheric ozone depletion (Cariolle et al., 1989; Carslaw et al., 1998). Mountain wave-induced adiabatic expansion of air along tilted isentropes can lead to temperature differences of up to $13 \mathrm{~K}$ as compared to analyses which do not contain the wave signals (Dörnbrack et al., 1999) and may allow stratospheric temperature to drop below the ice formation threshold. Recently, Hitchman et al. (2003) proposed an alternative gravity wave (GW) forcing mechanism for PSC formation: GWs emitted from breaking Rossby-waves at the tropopause level can also lead to mesoscale temperature fluctuations in the stratosphere sufficient to cool below the frost point $\left(T_{\text {ice }}\right)$.

This article will report on an ice PSC recorded by the NASA DC-8 lidar during the transfer flight on 14 January 2000 from the NASA Dryden center to Kiruna (Northern Sweden), where the SOLVE/THESEO (SAGE III Ozone Loss and Validation Experiment/Third European Stratospheric Experiment on Ozone) campaign was hosted. It was the only stratospheric ice-cloud observed over Greenland during the entire deployment. The temperatures from global analyses (i.e. from the European Center for MediumRange Weather Forecast, ECMWF) are several degrees too high to explain the occurrence of ice at a height of about 


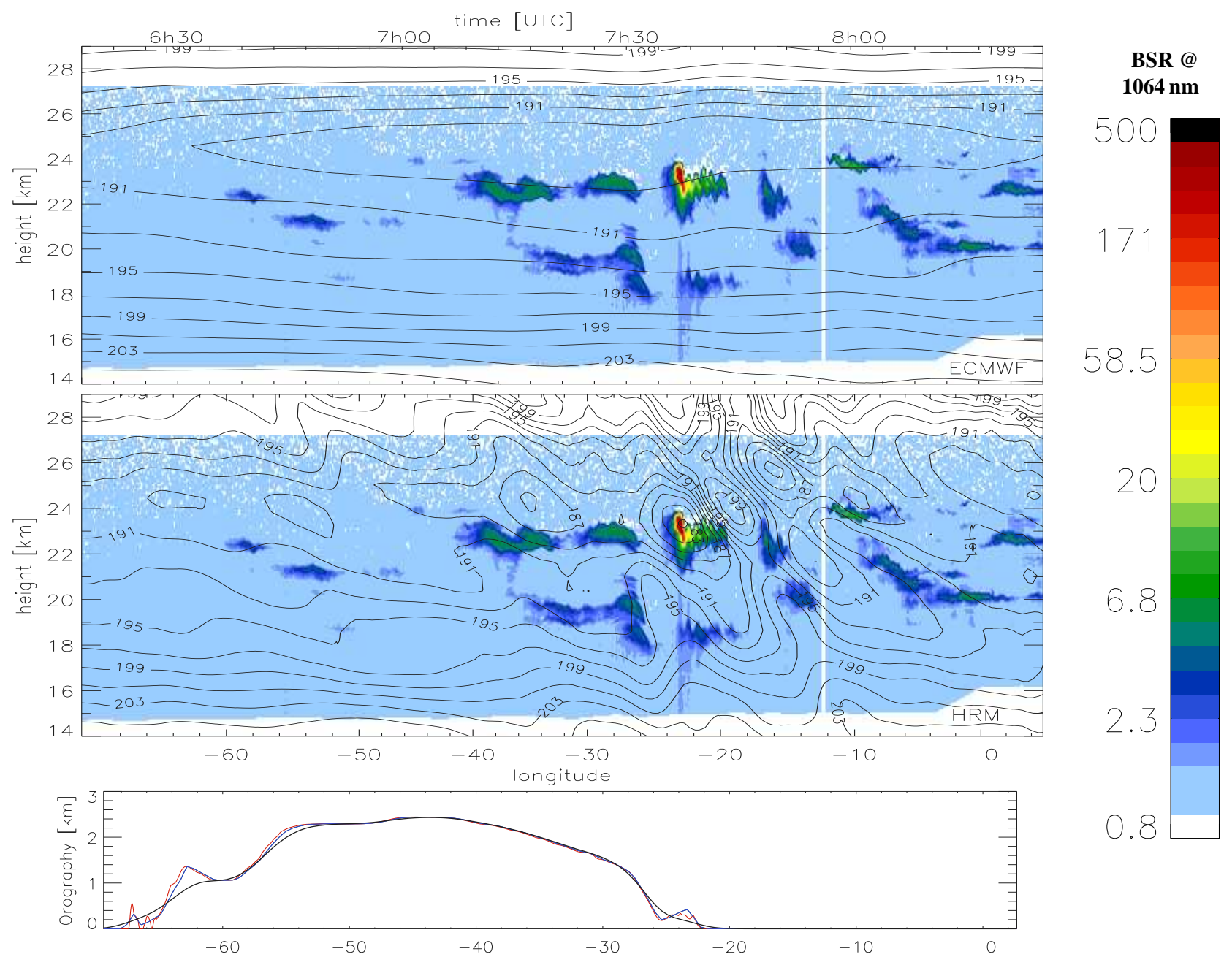

Fig. 1. Backscatter ratio (BSR) at $1064 \mathrm{~nm}$ from the DC-8 LaRC lidar during a flight over Greenland on 14 January 2000. Overlayed are the 4-D interpolated temperature fields from (top) the ECMWF analyses and (middle) the HRM mesoscale model simulation (contour interval $2 \mathrm{~K}$ ). The lower panel displays the underlying orography with resolutions of $0.0125^{\circ}$ (red line), $0.125^{\circ}$ (blue line) and $0.125^{\circ}$, Gaussian filtered (black line, as used in the simulation). The flight path is shown by the orange line in Fig. 4 (top).

$23 \mathrm{~km}$ (see Fig. 1, top). A mesoscale GW that is not resolved by global models could lead to the needed temperature decrease. This cloud observation (i) provides the fortuitous opportunity to investigate the capability of mesoscale models to realistically simulate the stratospheric temperature field over the complex and large-scale topography of Greenland and (ii) motivates the investigation of the dynamical mechanisms that were responsible for the generation of small scale patches with temperature $T$ below $T_{\text {ice }}$. The main focus of the present study are the dynamics and modeling capabilities. The reader is referred to Luo et al. (2003) for thorough microphysical considerations of this ice cloud. Few hours after the DC-8 observation the NASA ER-2 aircraft also crossed Greenland during its transfer flight and observed an enhanced wind and temperature variance. This also could be attributed to a GW and delivers a further validation opportunity for the mesoscale model. In the remaining of the introduction some general background on gravity wave generation mechanisms - a key aspect of the present study - is provided.

Gossard and Hooke (1975) review the following mechanisms that can act as energy sources for GWs: convection, density impulses (accelerating fronts), geostrophic adjustment, topographical forcing and vertical shear instability. Of particular relevance for the present study are the processes of adjustment and shear instability. They are both poorly understood and not necessarily related to each other (cf. McIntyre, 2003).

Several articles report observations of inertia GW that emanated from vertical shear instabilities or spontaneous adjustments, e.g. Thomas et al. (1999); Pavelin et al. (2001); Hertzog et al. (2001); Peters et al. (2003); Plougonven and Teitelbaum (2003). The characteristics of these waves were $\sim 100-1000 \mathrm{~km}$ horizontal wavelength, $1.5-12 \mathrm{~km}$ vertical wavelength and $10-23 \mathrm{~h}$ for the ground based wave period. 
In the cases discussed by Shibata et al. (2003) and Hitchman et al. (2003), the GWs were induced near the level of the jet stream and led to the formation of PSCs as observed by lidars. Uccellini and Koch (1987) analyzed 13 cases of wave events over the USA with horizontal wavelengths $50<\lambda_{h}<500 \mathrm{~km}$ and investigated the typical synoptic setting (jet streak approaching an upper-level ridge) and the possible source mechanisms (shear instability and geostrophic adjustment). Analyzing eight cases of observed mesoscale variance enhancements in the temperature and horizontal wind velocity, Fritts and Nastrom (1991) found one case each due to topography and jet-stream instability. These two cases showed the largest mean variances in wind and temperature.

Using a hydrostatic spectral model O'Sullivan and Dunkerton (1995) were able to simulate the life cycle of an initially balanced baroclinic wave, generating inertia GW, by spontaneous adjustment near the level of maximum wind speed, in the vicinity of the jet-stream exit region. In an other idealized setup, Sutherland and Peltier (1995), using nonlinear incompressible Boussinesq-flow simulations restricted to two dimensions, pointed out that a precondition for the onset of a Kelvin-Helmholz instability is that the maximum shear on the upper flank of the jet, which typically is situated near the tropopause, is shifted downward by about $1 \mathrm{~km}$ into a region in which the static stability is small. By reviewing observations, theory and model studies, Knox (1996) showed a stark connection between strongly anticyclonic flow situations and GW activity. He also pointed out the possibility of GW emission by adjustment and, as an alternative process, by inertial instability in regions of negative potential vorticity. With a two-dimensional incompressible Boussinesq model, Scinocca and Ford (2000) were able to simulate the Kelvin-Helmholz instabilities of the shear layer that engenders large-scale GW radiation.

In order to investigate the dynamical mechanisms that lead to the generation of observed GWs over Greenland on 14 January 2000, we have performed meteorological simulations, comprising the entire island. Mesoscale simulations of the southern tip of Greenland, for a mountain wave event reaching the stratosphere in 1992, including validation with observations (which were presented and discussed by Chan et al., 1993) were already performed by Leutbecher and Volkert (2000).

In the following section, the limited-area model and its setup are presented. The lidar ice-cloud observations are shown in Sect. 3. Then, in Sect. 4, the second GW signature measured on the same day is introduced and the mesoscale simulations compared with observations. In Sect. 5 the mechanisms that produced both GWs are investigated and the wave signatures found in the mesoscale numerical experiment interpreted. Backward ray trajectories are displayed and discussed in Sect. 5.3. The more general potential for jet-induced GWs which might lead to PSC formation is estimated for one winter season in Sect. 6 .

\section{Meteorological models}

In the following subsections the model data utilized in this study are described.

\subsection{ECMWF analyses}

The ECMWF operates a spectral meteorological model and uses a four-dimensional variational data assimilation scheme (4-D var) since November 1997 (Rabier et al., 2000). It makes use of the advanced microwave sounding unit data which greatly improved the Arctic stratospheric temperatures (ECMWF, 1999). The triangular truncation version T319 (corresponding to a grid size of $\sim 60 \mathrm{~km}$ ) has been introduced in April 1998 and additional vertical levels in March 1999. Since then, the ECMWF model includes 60 levels, of which typically about 30 are in the stratosphere i.e. above the $2 \mathrm{pvu}$ (potential vorticity units, $10^{-6} \mathrm{~m}^{2} \mathrm{~s}^{-1} \mathrm{~K} \mathrm{~kg}^{-1}$ ) tropopause for the considered latitudes and season.

These 6-hourly ECMWF analyses provided the initial conditions and lateral boundary data for the mesoscale simulations described below.

\subsection{HRM}

\subsubsection{The model}

The limited-area high resolution model (HRM) is the successor of the Europa-Modell (EM, Majewski, 1991). The EM was used operationally by the German and Swiss Weather Services until early 2001. In the hindcast mode, it is intensively applied for regional climate simulations (e.g. Lüthi et al., 1996). In this climate version, a 15 -year integration over Europe revealed a good agreement of simulated precipitation with observations and other limited-area models (Frei et al., 2003). During the SOLVE/THESEO deployment, the HRM produced daily quasi-operational stratospheric forecasts to help mission planing. Fueglistaler et al. (2003) examined the mountain wave induced PSC event over Scandinavia on 25 January 2000 (see also Dörnbrack et al., 2002). Using a microphysical box model and trajectories from a HRM simulation, they could realistically reconstruct the observed lidar signals associated with the PSC.

The HRM integrates the set of primitive equations in the hydrostatic limit in hybrid pressure coordinates (terrainfollowing sigma coordinates near the ground and constant $p$ levels in the stratosphere). The prognostic variables are perturbation pressure, temperature, the three wind components as well as specific humidity and cloud liquid water content. The full physics form includes parametrizations of radiation and convection (Majewski, 1991).

A linear fourth order diffusion is applied in the horizontal to ensure numerical stability. The diffusion is scale selective, where only the waves up to four times the mesh width are noticeably attenuated. As the fourth order diffusion corresponds to a five points-operator, a second order diffusion 
is applied at the borders of the domain. In the vertical direction, the diffusion parametrization is based on a flux-gradient approach in which the turbulent vertical fluxes are proportional to the vertical gradient of the variable to be attenuated and a diffusion coefficient. The computation of the turbulent vertical diffusion coefficients is based upon the second order closure of the equations for higher moments.

The HRM has been tested for flow past obstacles in idealized conditions (Lüthi, 1994). The response of a uniform, constantly stratified, adiabatic and inviscid flow to a bellshaped, isolated mountain was found to be in good agreement with analytical solutions. The radiative upper boundary condition of the model based on Bougeault (1983) and Klemp and Durran (1983) (see Herzog, 1995, for its application to hybrid coordinates) was found suitable and showed no sign of spurious reflection.

\subsubsection{Setup of the Greenland simulations}

A dry physics simulation without convection was initialized on 13 January 2000, 12:00 UTC which includes the other parametrizations (soil processes, radiation and turbulence). It is performed for $30 \mathrm{~h}$ with a computational time step of $25 \mathrm{~s}$ and output is produced every hour. Sensitivity experiments, for a wide range of parameters (which will be discussed in the Appendix), showed for instance that inclusion of moist thermodynamics and the exclusion of radiation, in the present case, have little or no effect on modeling the generation of GWs and their propagation into the stratosphere.

The model orography is derived from the $30^{\prime \prime}$ spaced elevation data set from the US Geological Survey, Sioux Falls, South Dakota. For the present simulation, a Gaussian filter is applied to the orography in order to reduce the short wavelength contributions to the mountain waves (see Fig. 1) as finite differencing errors are large for waves with wavelength close to twice the mesh width.

In the stratosphere a relatively high vertical resolution is necessary in order to resolve GWs, as their vertical wavelength might become small due to high static stability and vertical wind shear. Therefore an equidistant level spacing of approximately $\Delta z \approx 700 \mathrm{~m}$ has been chosen throughout the model atmosphere. (This vertical resolution is at the lower limit, but could not be increased further for such a large domain due to computational restrictions.) There are 60 vertical levels in total with the model top at $2 \mathrm{hPa}$ $(\sim 42 \mathrm{~km})$. The horizontal resolution is $\Delta x=0.125^{\circ}$ which corresponds to $\sim 14 \mathrm{~km}$ and the simulation comprises the entire island of Greenland $(145 \times 201$ grid points, see Fig. 4 for a view of the domain). Simulations for such large a domain $(\sim 1800 \times 2800 \mathrm{~km})$ are challenging and the lidar and ER-2 in-situ observations provide the possibility to validate aspects of the numerical experiments.

\section{Ice cloud above Greenland on 14 January 2000}

\subsection{Lidar observation}

During the forementioned flight, the NASA DC-8 LaRC Aerosol lidar (a piggy-back instrument measuring backscatter ratios at $354 \mathrm{~nm}$ and $1064 \mathrm{~nm}$ as well as depolarization at $532 \mathrm{~nm}$ ) recorded both types of PSCs above Greenland. The lidar recordings of the flight segment within the mesoscale simulation domain (see Fig. 4) are shown in Fig. 1. For a backscatter ratio at $1064 \mathrm{~nm}$ greater then 50 (red), water ice (PSC type II) can safely be assumed due to the large amount of condensated mass, and lower values (backscatter ratio lower than 30, green and dark blue) indicate the presence of supercooled ternary solution droplets (PSC type I). The ice cloud near $23^{\circ} \mathrm{W}, 77^{\circ} \mathrm{N}$ at an altitude of $\sim 23 \mathrm{~km}$ (corresponding to $\sim 25 \mathrm{hPa}$ or $\sim 520 \mathrm{~K}$ ) has a horizontal extension in the aircraft flight direction of $\sim 50 \mathrm{~km}$ and is the central feature of the present investigation. Its horizontal location is indicated in Fig. 4 (top, orange circle) and is close to the eastern coast of Greenland.

The ECMWF temperatures (overlayed contours in the upper panel of Fig. 1) are too high to allow ice formation: at the height of the observed ice cloud the ECMWF temperature is $\sim 189 \mathrm{~K}$ which is more than $3 \mathrm{~K}$ above the frost point at $25 \mathrm{hPa}$ (assuming a water mixing ratio of $6 \mathrm{ppmv}$ ). For the homogeneous nucleation of ice particles, temperatures even $\sim 3 \mathrm{~K}$ below the frost point (i.e. $\sim 183 \mathrm{~K}$ ) are required (Koop et al., 2000).

The disposition of the single PSC lidar signals suggests that gravity waves could account for the regular appearance of the required cold patches, namely with a vertical and horizontal wavelengths of the order $\lambda_{z} \sim 4 \mathrm{~km}$ and $\lambda_{h} \sim 180 \mathrm{~km}$. Closer inspection of the ice cloud reveals that a wave train with much smaller scale, $\lambda_{h} \sim 15 \mathrm{~km}$, is superimposed. We hypothesize that this fine-scale features are associated with vertically propagating non-hydrostatic GWs triggered by the complex structure of the underlying topography. However, these structures have too small a scale to be resolved by a hydrostatic model for the entire Greenland island. Therefore, the model analyses will be restricted to the interpretation of the ice cloud as a whole and not consider its internal structure.

\subsection{Air trajectory}

The cooling rate of air parcels involved in the PSC formation is an important factor determining the cloud's microphysical composition. Here we use the HRM simulation output which (in contrast to ECMWF) provides a realistic stratospheric temperature field for this particular case (as discussed in Sect. 4).

In order to estimate the cooling rate that air parcels undergo as they become part of the ice cloud, we computed an air trajectory from the location $\left(22.6^{\circ} \mathrm{W}, 77.3^{\circ} \mathrm{N}\right)$ and 

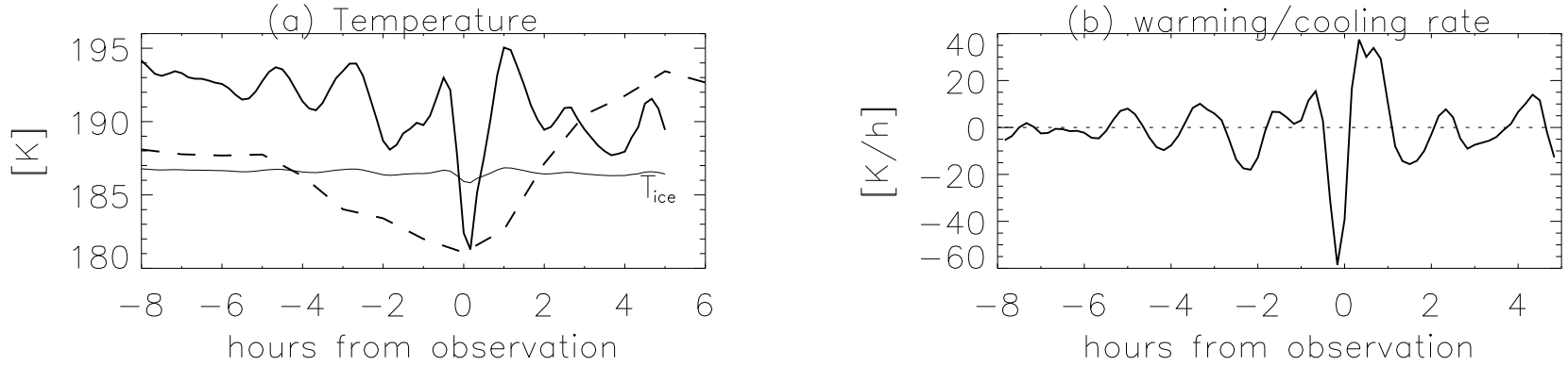

Fig. 2. Temperature in $\mathrm{K}$ (a) and warming/cooling rate in $\mathrm{Kh}^{-1}$ (b) along the air trajectory started at the time and location of maximum observed backscatter ratio. The dashed line in panel (a) indicates the time evolution of HRM temperature at the trajectory's starting point.

time (08:00 UTC) of maximum observed backscatter ratio (cf. Fig. 1), backward and forward in time, with the HRM wind fields. A description of the trajectory calculation tool can be found in Wernli and Davies (1997). The temperature as well as the cooling/warming rate along the trajectory are shown in Fig. 2 and the horizontal trace of the trajectory is drawn in Fig. 4 (top, black line). The air parcel's temperature oscillations have a time scale of about 2 hours while traveling over Greenland, possibly due to GWs, and only for a short time period $(<1 \mathrm{~h})$ temperature goes below $T_{\text {ice }} .1 \mathrm{~h}$ after the occurrence of the PSC the air has warmed by $13 \mathrm{~K}$ and $T$ exceeds also the threshold for the existence of NAT. Note also in Fig. 2a the striking difference of the temperature experienced by the PSC air parcel and the more slowly varying local temperature evolution. As a consequence, during the short time needed for the air parcel to cross the cold region, the wave can be regarded as frozen.

The cooling rate (Fig. 2b) at the onset of nucleation controls the resulting ice particle number density. Here, the high rates $\left(>40 \mathrm{Kh}^{-1}\right)$ lead to freezing of the great majority of the liquid ternary solution droplets, resulting in an ice PSC with particle number density $n \sim 10^{1} \mathrm{~cm}^{-3}$ (Fueglistaler et al., 2003). This cooling rate stays in good agreement with the ones found by Luo et al. (2003), who derived an air trajectory from the lidar PSC measurement.

The calculated cooling rates exceed the ones quoted by Shibata et al. (2003) and would not lead to substantial dehydration due to the small particle sizes and the short lifetime of the ice particles of $\sim 0.5 \mathrm{~h}$. The sedimenting velocity of particles with radii $\sim 1 \mu \mathrm{m}$ is about $1 \mathrm{mh}^{-1}$, thus the fall distance is less than $1 \mathrm{~m}$. It has been suggested that NAT can nucleate on ice particles (Carslaw et al., 1998; Luo et al., 2003). Based on the temperature history along the trajectory (Fig. 2a), the air parcel remains below the equilibrium temperature for NAT (Hanson and Mauersberger, 1988) only about one hour and thereafter particles will evaporate rapidly. This duration is too short for substantial denitrification induced by this particular ice cloud. A detailed discussion of the microphysical life cycle of other PSC particles can be found in Fueglistaler et al. (2003) and Luo et al. (2003).

\subsection{The synoptic situation}

Here, using ECMWF analysis data, we present the synoptic situation in the region of Greenland during the hours prior to the ice cloud observation. From 13 January 18:00 UTC (Fig. 3a) through 14, 06:00 UTC (Fig. 3b) and further to 15, a pronounced upper tropospheric ridge shifts northeastwards from the southeast of Greenland, as seen by the protruding tongue of low PV air on the $320 \mathrm{~K}$ isentrope. This ridge initiated already on 12 January 2000 and transformed into a mid-tropospheric anticyclone on 16 with closed $500 \mathrm{hPa}$ geopotential isolines (not shown). This anticyclone is associated with a negative upper-level PV-anomaly (Schwierz, 2001) and remains quasi-stationary between Greenland and Europe until 25 January.

The jet-stream which goes along with the region of maximum PV gradients is very intense and strongly curved anticyclonically. On the $370 \mathrm{hPa}$ surface, wind speeds exceed $60 \mathrm{~ms}^{-1}$ in the vicinity of the tropopause (see the blue contours). At 18:00 UTC 13 January (Fig. 3a), there is strong deflection between the $\mathrm{S}-\mathrm{N}$ aligned jet streak south of Greenland and the westerly jet streak across Greenland further north. $12 \mathrm{~h}$ later (Fig. 3b), upper level winds blow about parallel to the SE coast of Greenland and a northerly jet streak has formed NE of Iceland. Generally, the synoptic situation in the Greenland region has a strong non-stationary character during this time period as confirmed in Fig. 6 displaying the time evolution of the wind profiles at the location of the ice cloud.

In the lower troposphere, a slowly evolving low-pressure system (which is not associated with convection) develops from 13 to 15 January on the south-western tip of Greenland producing a southerly surface flow south of the island (see wind vectors in Fig. 3). These intense low-level winds (up to $20 \mathrm{~ms}^{-1}$ ) favor the orographic generation of vertically propagating GWs, at least in the south and middle of the island, the situation in the north being more complex.

At around $26 \mathrm{~km}$ height the vortex edge is approximatively zonally aligned (see purple contours in Fig. 3). Parallel alignment of the tropospheric and stratospheric jets privileges the 

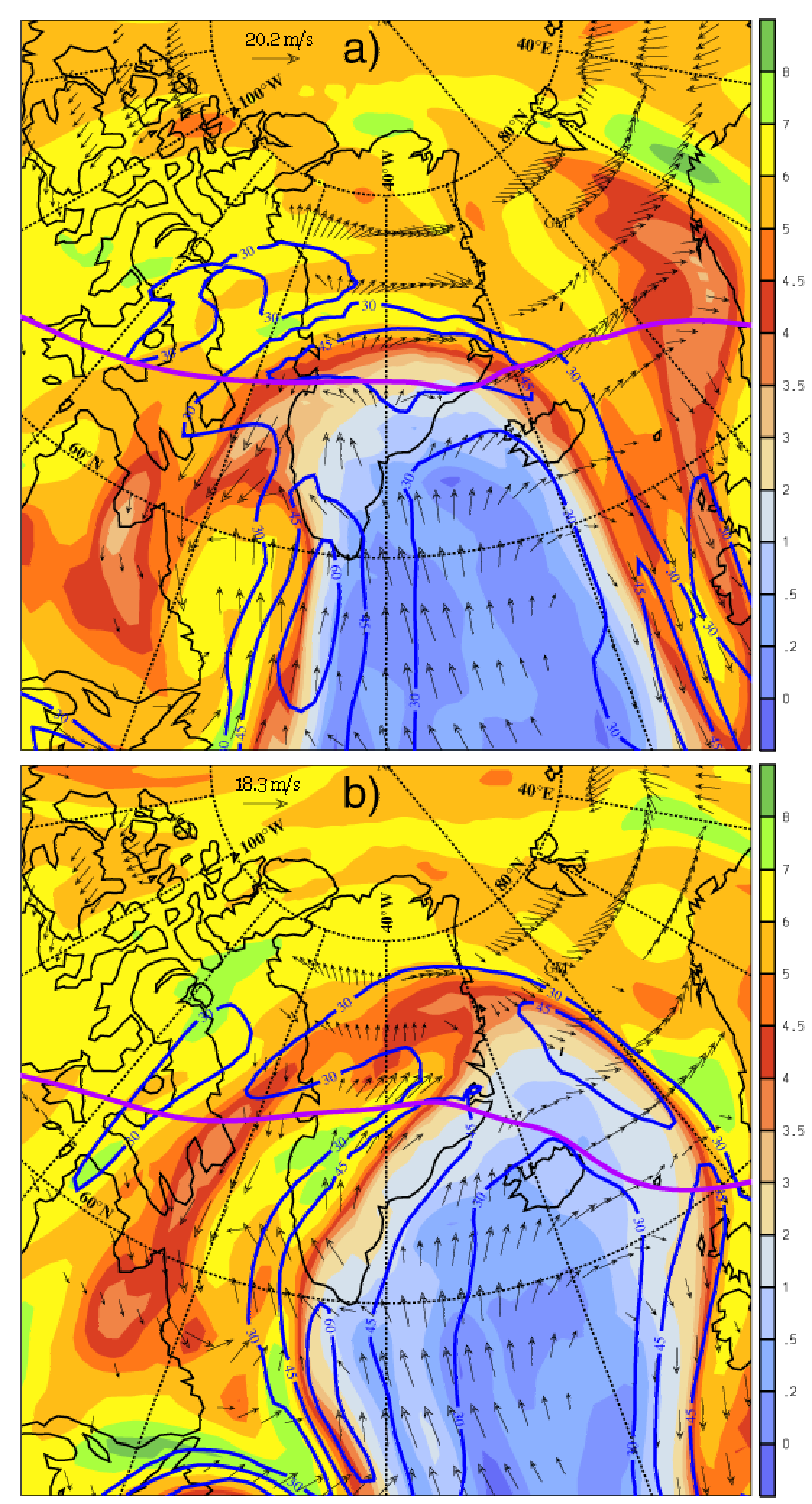

Fig. 3. The synoptic situation on 13 January, 18:00 UTC (a) and 14 January, 06:00 UTC (b) from ECMWF analysis data. Color: potential vorticity [pvu] at $320 \mathrm{~K}$, blue contours: wind speed at $370 \mathrm{hPa}$ (isolines for 30, 45 and $60 \mathrm{~ms}^{-1}$ ) and black vectors: wind vectors at the model lowermost level if velocity $>5 \mathrm{~ms}^{-1}$, south of $80^{\circ} \mathrm{N}$. The violet contour denote the vortex edge on the $665 \mathrm{~K}$ isentrope.

vertical propagation of GWs (irrespective of the generation mechanism) and can lead to enhanced GW-induced temperature perturbations in the stratosphere (Whiteway and Duck, 1999).

\section{Wave signatures in the HRM simulations}

In this section GW structures in the HRM simulation are explored. The focus is (i) on the GW that led to the formation
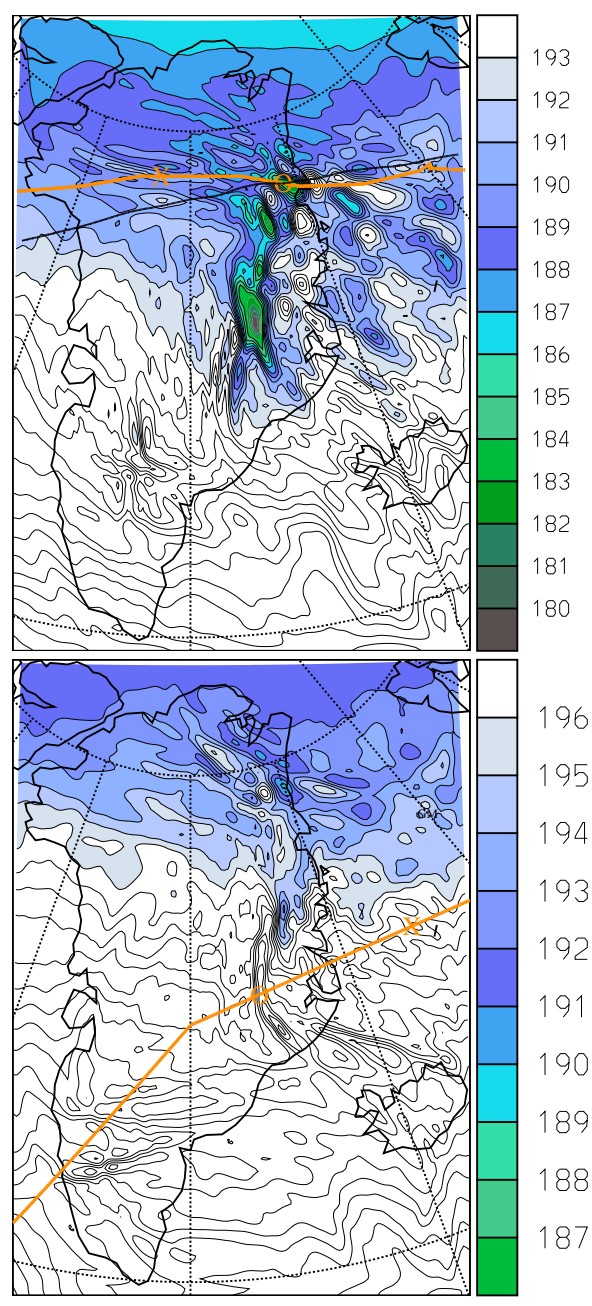

Fig. 4. Mesoscale temperature $[\mathrm{K}]$ fields from the HRM simulation on 14th of January 2000, 07:00 UTC ( $23 \mathrm{~km}$ height, top) and 18:00 UTC, at the cruise altitude of the ER2 (19.3 km, bottom). Regions with $T<T_{\text {ice }}(\simeq 186.2 \mathrm{~K}$, top and $\simeq 188.7 \mathrm{~K}$, bottom) are shown in green and the regions with $T<T_{\mathrm{NAT}}(\simeq 191.6 \mathrm{~K}$, top and $\simeq 195.2 \mathrm{~K}$, bottom) are displayed in blue. Orange overlayed lines are the DC-8 (top) and ER-2 flight pathes (bottom). The crosses denote the locations of the airplanes at the model output time. The circles denote the position of the observation of gravity wave signatures. The black line in the top panel is the horizontal trace of the air trajectory shown in Fig. 2.

of the ice PSC observed by the lidar on board the DC-8 (this GW will be referred to as 'wave DC8' hereinafter), and (ii) to GWs identified from the ER-2 in-situ measurements (in the following 'wave ER2'). The observations serve also to quantitatively validate aspects of the model simulation.

\subsection{Horizontal views of mesoscale temperatures}

A horizontal view of the HRM temperature field at the time (07:00 UTC 14 January, $17 \mathrm{~h}$ after the start of the simulation) 
and height $(23 \mathrm{~km})$ of the maximum observed lidar backscatter ratio indicates rich mesoscale patterns (Fig. 4, top). Several spots exist over Greenland with stratospheric temperatures low enough to allow PSC type II formation $(T<183 \mathrm{~K})$. Vertical sections through these potential locations of iceclouds (not shown) exhibit evidence that these cold spots are induced by different GW with clearly differing characteristics as horizontal and vertical wavelengths (see also Sect. 5.3.1, where the wave characteristics will be specified quantitatively). Note that the southernmost cold location $\left(\sim 32^{\circ} \mathrm{W}, \sim 72^{\circ} \mathrm{N}\right)$ has been sampled by the ER-2 about eleven hours later, when the wave activity has weakened in the mesoscale model. Figure 4 (bottom) shows the HRM temperatures at the time (18:00 UTC) and flight altitude $(19.3 \mathrm{~km})$ of the ER2 observation. Here also, the HRM produces vertically propagating GWs at the location of temperature and wind variance enhancement observed by the ER-2 (Fig. 5).

\subsection{Model validation with observations}

The vertical section of HRM temperature along the DC-8 flight path (Fig. 1, bottom) reveals clear GW signals leading to large deviations from the ECMWF analyses (compare with Fig. 1, top). Near $23^{\circ} \mathrm{W}$, the mesoscale simulation produces a temperature minimum $8 \mathrm{~K}$ colder than the analyses (and $\sim 4.5 \mathrm{~K}$ below the frost point), at the exact location of the ice cloud. This is in good agreement with Luo et al. (2003) who estimated mesoscale temperature variations of $\pm 7 \mathrm{~K}$ with respect to the ECMWF analyses, by matching backscatter ratio of ice particles obtained from a microphysical model to the measured backscatter ratio aboard the DC- 8 . The horizontal and vertical extension of the ice cloud, as seen in the lidar plane, is also very well reproduced by the HRM. The other (type I) clouds observed by the lidar do not always exactly correspond to, but are close to a local HRM temperature minimum.

Aboard the ER-2, the meteorological measurement system (MMS) is collecting data with a sampling rate of $10 \mathrm{~Hz}$ and an uncertainty of $0.3 \mathrm{~K}$ for temperature and $1 \mathrm{~ms}^{-1}$ for the airspeed (Scott et al., 1990). This yields low-pass filtered data at a resolution of $1 \mathrm{~s}$ or $\sim 200 \mathrm{~m}$ horizontal distance at mean cruise speed. The MMS temperature, zonal and meridional wind observations are displayed in Fig. 5 along with the HRM simulation and ECMWF analyses interpolated in time and space to the flight path. The limitations of the HRM resolution $(15 \mathrm{~km}$ in space and $1 \mathrm{~h}$ in time) indicate that no perfect agreement with the observations can be expected on the smallest scales. The observations show enhanced temperature and wind variance around $30^{\circ} \mathrm{W}$ which can be identified as a GW signature, as noted by Chan et al. (1993). HRM temperatures and winds also show enhanced fluctuations at the right location, however with too long a horizontal wavelength. They oscillate around the driving ECMWF analyses, and thus, if the analyses are biased (positively at the begin-
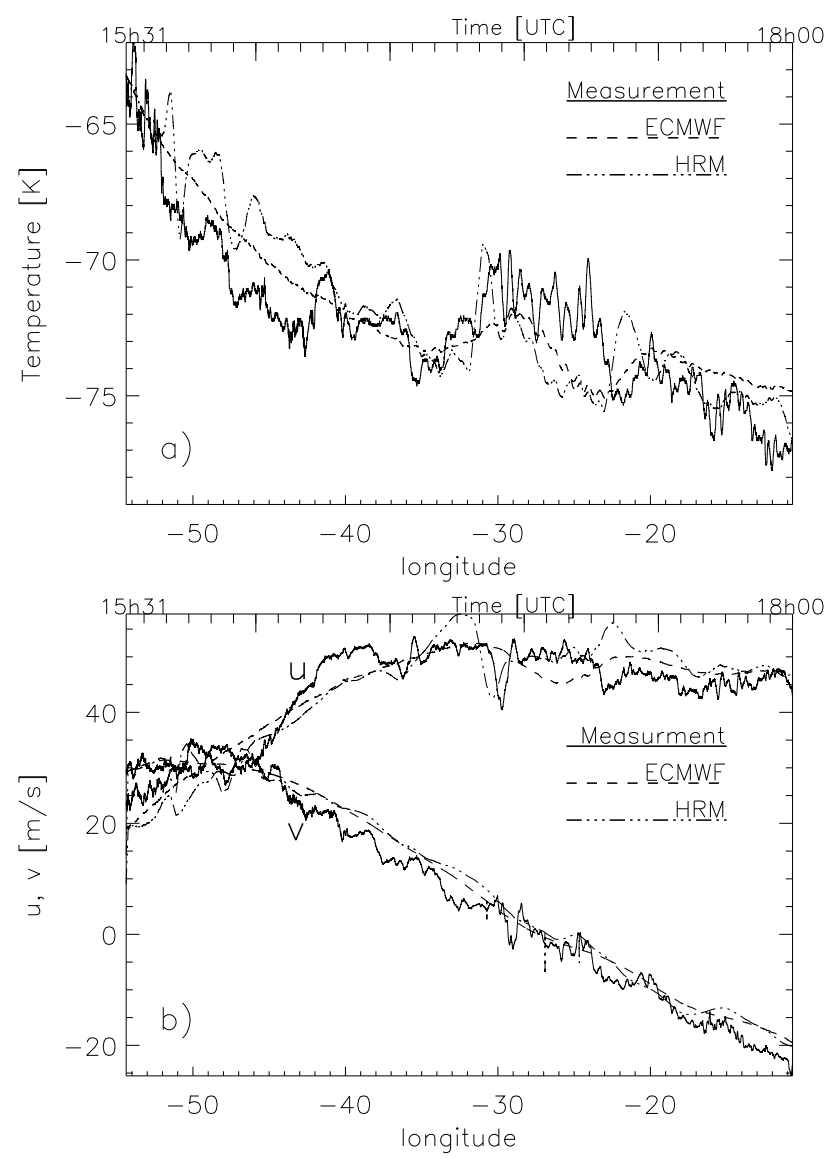

Fig. 5. Temperature (a) and zonal and meridional wind (b) measurements aboard the ER-2 aircraft on 14 January 2000 ( $1 \mathrm{~s}$ resolution) within the mesoscale simulation domain as well as ECMWF and HRM temperatures along the flight path which is shown in Fig. 4 (bottom).

ning and end of the considered flight segment) the (fluctuating) mesoscale temperatures and winds are likely to show the same bias. The overall HRM differences with respect to the observations are weakly positive for temperature (less than $1 \mathrm{~K}$ with a standard deviation of $1.7 \mathrm{~K}$ ) and slightly negative for wind velocity $\left(-0.7 \mathrm{~ms}^{-1}\right)$.

These qualitative and quantitative comparisons of HRM temperatures and winds with the available independent measurements, point to the capability of the HRM to produce accurate propagating GWs above Greenland up to the middle stratosphere and completes the validation of this HRM simulation.

\section{Interpretation of HRM wave signatures}

Various diagnostic techniques are applied to the HRM model output in order to obtain evidence for the origin of the two GW structures ('wave DC8', 'wave ER2') discussed in the last sections. The diagnostics include analysis of wind 

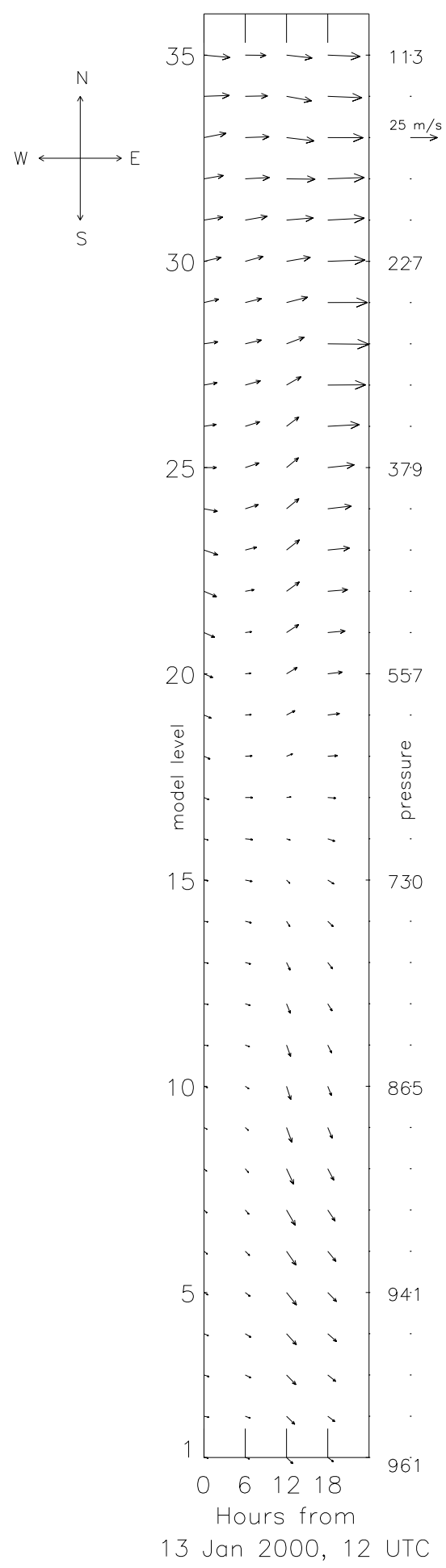

Fig. 6. Time and vertical evolution of the ECMWF wind intensity (arrow length) and wind direction (westerlies are horizontal arrows to the right) interpolated to the location of the ice cloud observation $\left(22.65^{\circ} \mathrm{W}, 77.32^{\circ} \mathrm{N}\right)$. On the right the mean pressure on the respective ECMWF model levels is given. profiles, investigation of the horizontal divergence of the wind field patterns and detailed GW ray tracing calculations.

\subsection{Wind profiles}

We first look at the time evolution of the background wind profiles from ECMWF analyses interpolated to the location of the ice cloud observation. Note the high unstationarity of the wind profile and the strong wind around $250 \mathrm{hPa}$ in Fig. 6, even at this high latitude. The change of wind direction with height of more than $90^{\circ}$ in the layer from 900 to $500 \mathrm{hPa}$ on the 14 January 2000, 00:00 UTC points to the existence, at least for stationary waves, of a critical layer. Such a layer exists where the background wind matches the phase speed of the wave, and it can prevent mountain waves to propagate upward into the stratosphere. As mentioned above, the small scale undulations seen in the backscatter signal (Fig. 1) might be caused by orographic waves. But they would have to propagate vertically without encountering a critical surface, that is prior or after the occurrence of this critical layer, or, get their way through the troposphere not literarily vertically. In contrast, for 'wave ER2' the wind direction changes less with height and the wind profile allows vertical wave propagation from the surface to the middle stratosphere (not shown). These wind profiles are a first indication that 'wave ER2' can be a vertically propagating mountain wave whereas 'wave DC8' might not.

\subsection{Divergence along flight tracks}

The horizontal wind divergence calculated from the HRM simulations is shown in Fig. 7 along the two flight paths for 14 January 07:00 UTC (top, 'wave DC8') and 18:00 UTC (bottom, 'wave ER2'). The alternation of convergence and divergence as well as the back tilt of the constant phase lines are characteristic of vertically propagating GWs. For 'wave ER2', vertical coherency is obvious from the Greenland mountains to the model top and thus, this wave is due to an orographic forcing. For 'wave DC8', the patterns are in line with the indications from the previous section: that this wave is not a mountain wave. According to Fig. 7 the origin of the wave might be situated in the upper troposphere. This is confirmed by careful inspection of many vertical divergence sections in other planes (not shown). A set of crosssections centered at the cloud observations and sections perpendicular to the flight route for the entire HRM-simulation time span reveal that there is no mountain wave resolved by the model in the vicinity of the section presented in Fig. 7. They also show that the displayed signature in Fig. 7 is not the remnant of a mountain wave excited hours before. Note that from Fig. 7, 'wave DC8' appears to be horizontally more extended and has a larger horizontal and a smaller vertical wavelength than 'wave ER2'.

Figure 8 shows the same vertical sections as Fig. 7, but for a HRM experiment for which the height of the Greenland 


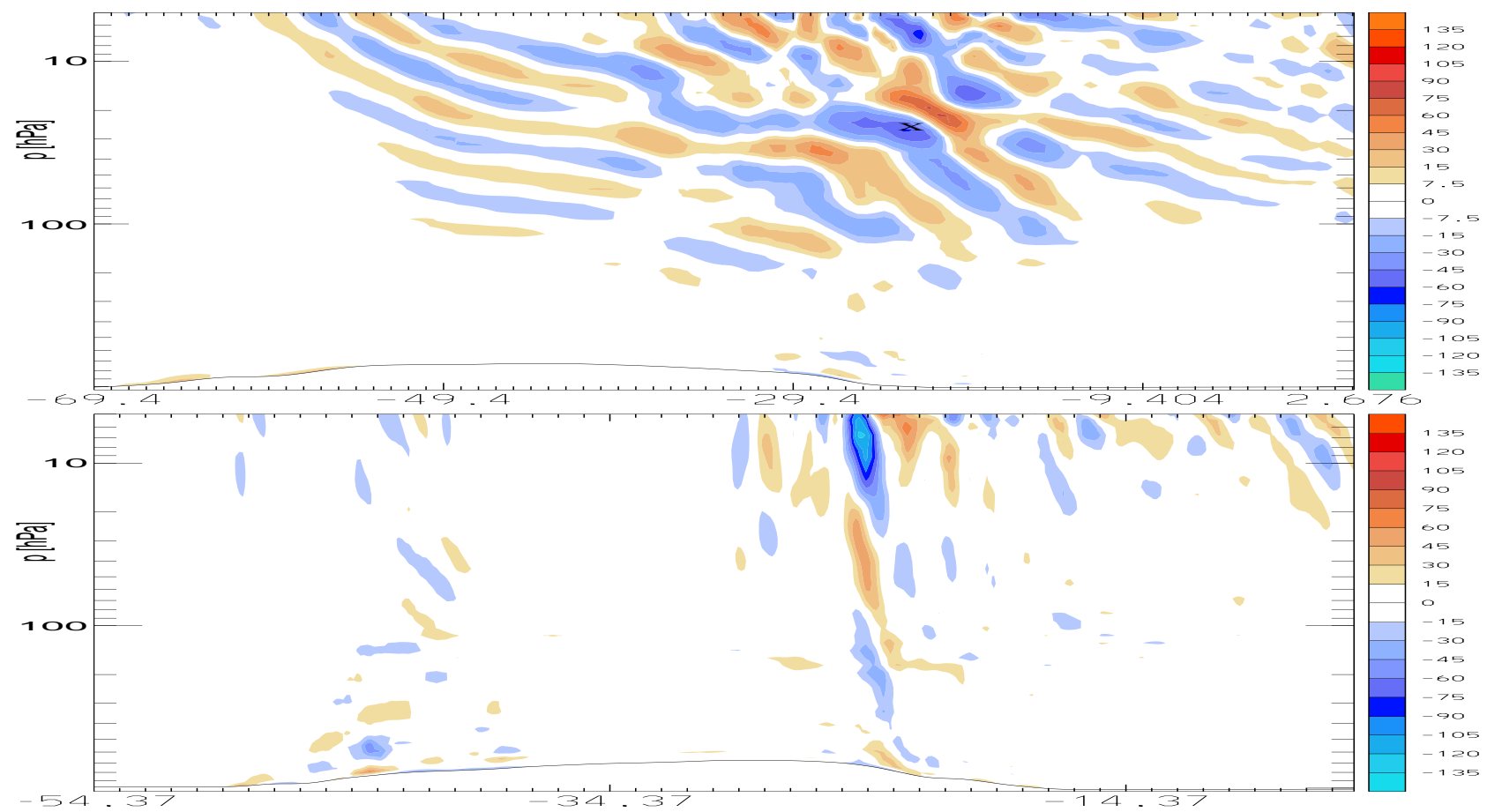

Fig. 7. Divergence (blue) and convergence of the horizontal wind from the HRM simulation $\left[10^{-5} \mathrm{~s}^{-1}\right]$ along the DC-8 (top, 07:00 UTC) and ER-2 (bottom, 18:00 UTC) flight paths on 14 January 2000 as a function of longitude and pressure. The black cross in the upper panel shows the location of the observed ice PSC. The lower solid curve reproduces the smoothed model orography.

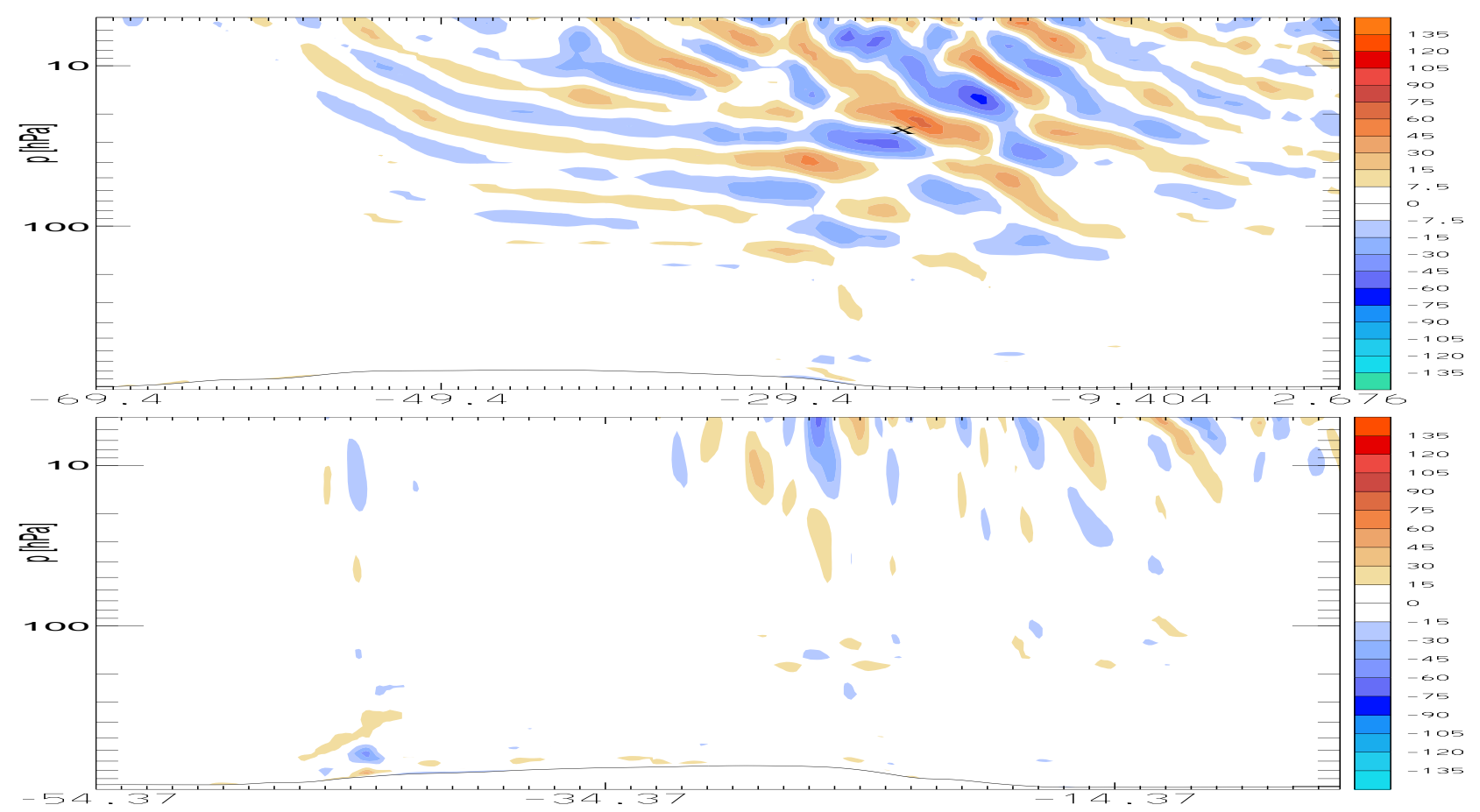

Fig. 8. Same as Fig. 7 but for a HRM simulation for which the orography has been uniformly reduced by $25 \%$. 
topography has been reduced by $25 \%$, leading to a maximum Greenland elevation of 2367 instead of $3155 \mathrm{~m}$. It shows that while 'wave DC8' is scarcely affected, the divergence signature of 'wave ER2' almost disappears in this sensitivity experiment. This gives a further clue to the above hypothesis about the waves' origins.

In order to further corroborate the jet-stream origin of 'wave DC8', backward ray trajectories will be computed in the next section.

\subsection{GW ray tracing}

Here we apply the GW ray tracing technique to our 'wave DC8' case. This technique has proven to be useful for determining the source of GWs observed in the stratosphere. (Hertzog et al., 2001). The version of the ray-tracing equations applied here is (Jones, 1969; Lighthill, 1978; Hertzog et al., 2001):

$\frac{d x_{i}}{d t}=\frac{\partial \omega}{\partial k_{i}}$

$\frac{d k_{i}}{d t}=-\frac{\partial \omega}{\partial x_{i}} \quad(i=1,2,3)$

with $\mathbf{x}=\left(x_{1}, x_{2}, x_{3}\right)$ the wave packet position, $\mathbf{k}=(k, l, m)=\left(k_{1}, k_{2}, k_{3}\right)$ the zonal, meridional and vertical wavenumbers and $\omega$ the wave's apparent frequency. This set of equations is complemented by the non-hydrostatic dispersion relation:

$m^{2}=\frac{N^{2}-\omega_{0}^{2}}{\omega_{0}^{2}-f^{2}}\left(k^{2}+l^{2}\right)$,

where $\omega_{0}$ is the wave's intrinsic frequency and $N$ the Brunt Väisäla frequency. Intrinsic and apparent frequency are further linked by the Doppler shift equation:

$\omega=\omega_{0}+k u+l v$,

with $u$ and $v$ the zonal and meridional wind components. The system of Eqs. (1) can be solved for a three-dimensional time-varying structure of the background fields, as exposed in Hertzog et al. (2001). The first equation of the system states that the wave packet trajectory is given by its groundbased group velocity, while the second equation expresses the refraction of the wave vector along the trajectory due to the inhomogeneities of the propagating medium (wind shear, variations of $N^{2}$ ). For the derivation of system (1), the WKB approximation is necessary: the properties of the background medium have to vary slowly on a time and length scale comparable to the wave parameters. In terms of vertical wind shear, the Richardson number of this propagating medium has to be sufficiently high.

In order to control the accuracy of the numerical scheme presented above, we first compare the wave packet frequency evolution obtained from the dispersion relationship (2) with a direct estimate of $\omega$, which is computed through integration of

$$
\frac{d \omega}{d t}=\frac{\partial \omega_{0}}{\partial N^{2}} \frac{\partial N^{2}}{\partial t}+\mathbf{k} \frac{\partial \mathbf{u}}{\partial t}
$$

in the same way as Eqs. (1), with $\mathbf{u}=(u, v)$. In the ensemble simulation presented below, both estimations do not differ more than $0.1 \%$ which gives confidence in the numerical scheme.

A second accuracy test is performed by reversing the ray trajectory simulation, i.e. we verify that taking the wave characteristics at the end of the backward integrations as initial conditions for a forward integration leads again to the terminal wave characteristics.

Finally, we also examine that the WKB approximation remains valid during the integration. As in Marks and Eckermann (1995), the validity of this assumption is checked by computing the Liouville-Green parameters which respectively measure the local rate of change of the zonal, meridional, vertical wavenumbers and intrinsic frequency. As an example,

$\alpha=\frac{1}{k^{2}}\left|\frac{\partial k}{\partial x}\right|$,

is the Liouville-Green parameter for $k$, the zonal wavenumber. The other parameters are computed analogously. These parameters are calculated during the integration of the ray equations and enable us to control the validity of our results. In the simulation presented below, these parameters are order 0.1 in the stratosphere and order unity in the vicinity of the tropospheric jet (not shown), where the accuracy is therefore smaller due to the strong vertical wind shear. The background fields (horizontal winds and static stability) necessary for the integration are taken from the ECMWF analyses.

To compute backward ray trajectories, the terminal wave specifications (direction of propagation, intrinsic frequency and vertical wavelength or the three wavenumbers at the time of observation) are requested. As the uncertainty in these terminal wave specifications is a large source of error, we computed an ensemble of backward ray trajectories with varied terminal conditions.

The way these wave characteristics are derived is exposed in the following section and then the result of the backward ray tracing simulation is presented.

\subsubsection{Wave specifications}

The following procedure has been applied to determine the characteristics of the (supposed monochromatic) wave packet at the time and location of the ice cloud observation. At this time and location, a vertical sounding has been performed through the HRM model atmosphere. The resulting zonal and meridional wind profiles are shown in Fig. 9a. The horizontal velocity vector rotates anticyclonically with 

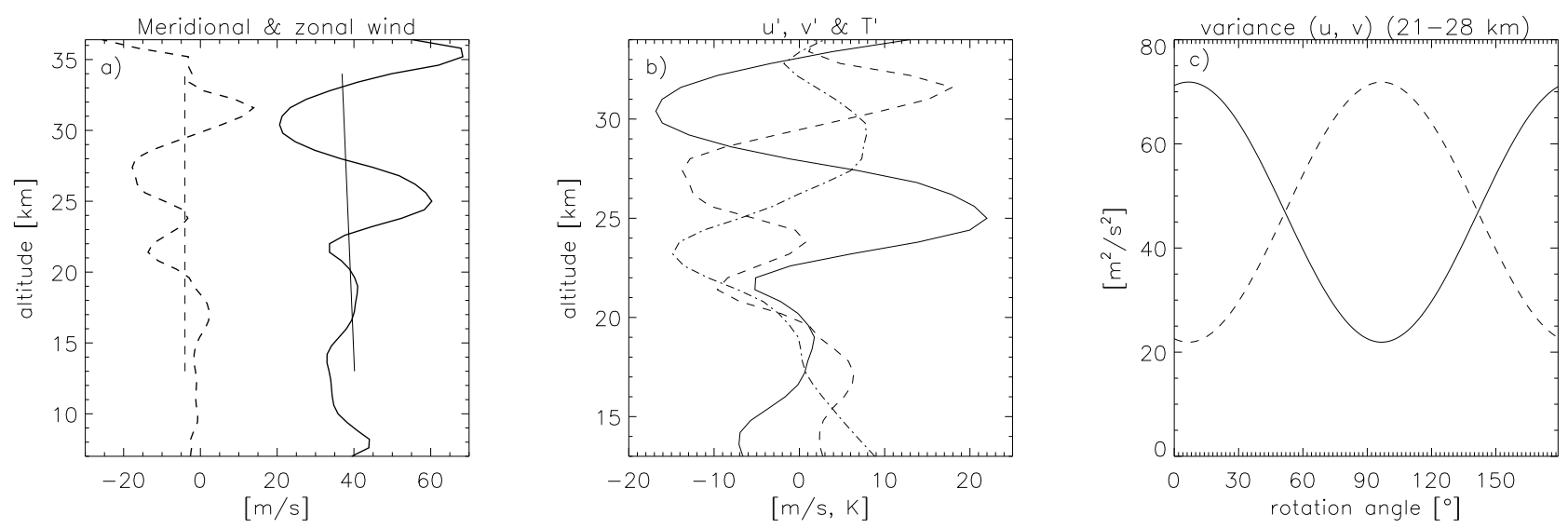

Fig. 9. Vertical profiles (using HRM data) at the location $\left(22.6^{\circ} \mathrm{W}, 77.3^{\circ} \mathrm{N}\right)$ and time (08:00 UTC) of maximum backscatter ratio observation. Panel (a) shows the zonal (solid) and meridional (dashed) wind components along with their (13-34 km height) fitted first order polynomial (thin lines), while the deviations thereto are represented in panel (b) along with the analogue temperature fluctuations (dash-dotted line). The parallel (solid) and perpendicular (dashed) wind variances are revealed as a function of the propagation angle in panel (c).

height, which is consistent with an upward energy propagation and a negative vertical wavenumber $m$ (using the convention that the intrinsic frequency $\omega_{0}$ is positive).

In order to derive the wind oscillations induced by the gravity wave, a linear fit (thin line in Fig. 9a within the range 13 to $34 \mathrm{~km}$ ) has been subtracted from the actual profiles. The resulting wind and temperature perturbations are displayed in Fig. 9b. For the present case, this method provided a more consistent and robust signal than the hodograph method used for instance by O'Sullivan and Dunkerton (1995) and Hertzog et al. (2001). Reasonable estimation for the vertical wavelength can be obtained from the different variables and height ranges (Fig. 9a or b) leading to $\lambda_{z}=8000 \pm 1200 \mathrm{~m}$.

Then, to determine the correct wave propagation angle, $\Theta$, we varied $\Theta$ between 0 and $179^{\circ}\left(0^{\circ}\right.$ stays for eastward wave propagation) and identified the angle with maximum variance of the parallel wind (see Fig. 9c). The wind components have therefore been projected to the parallel and perpendicular direction of the propagation angle, between 21 and $28 \mathrm{~km}$, which is the height range where the wave signal can clearest be identified in the considered sounding (see also Fig. 1). It turns out that a maximum exists for $\Theta=7^{\circ}$ for which the parallel wind variance (solid line) reaches $72 \mathrm{~m}^{2} \mathrm{~s}^{-2}$. There remains an ambiguity of $\pm 180^{\circ}$ about the propagation direction, which will be treated after estimating the magnitudes of the horizontal wave numbers. The polarization equations (Andrews et al., 1987),

$\left[\begin{array}{l}u^{\prime} \\ v^{\prime}\end{array}\right]=A[\mathbf{R}(\Theta)]\left[\begin{array}{c}\cos (m z+\phi) \\ -\frac{f}{\omega_{0}} \sin (m z+\phi)\end{array}\right]$,

state that the ratio between the propagation parallel and perpendicular wind variances are equal to $\omega_{0} / f$, where $f$ is the Coriolis parameter. $[R(\Theta)]$ is the rotation ma-
Table 1. Gravity wave packet specifications and uncertainties.

\begin{tabular}{cccc}
\hline$\Theta$ & $\omega_{0} / f$ & $\lambda_{h}[\mathrm{~km}]$ & $\lambda_{z}[\mathrm{~km}]$ \\
\hline$-173 \pm 4^{\circ}$ & $3.3 \pm 1.0$ & 384 & $8 \pm 1.2$ \\
\hline
\end{tabular}

trix which allows the phase speed to be aligned with the propagation direction, $A$ is the wave amplitude and $\phi$ a phase-shift. In our case, the ratio for $\Theta=7^{\circ}$ is $\omega_{0} / f=3.3$, which yields an intrinsic period of $2 \pi / \omega_{0}=3.72 \mathrm{~h}$, in agreement with the assumption of an inertio GW in the rotating wave regime $\left(f \lesssim \omega_{0} \ll N\right)$. Knowing that $|\tan \Theta|=|l / k|$, the horizontal wavelength can be estimated, leading to $\lambda_{h}=\frac{2 \pi}{\sqrt{k^{2}+l^{2}}}=384 \mathrm{~km}$.

The ambiguity in the group velocity direction of the wave, or in other words in the sign of the horizontal wave numbers can be removed with the help of the Doppler shift Eq. (3). At the cloud location and time of observation, the ECMWF analyses give $u \sim 45$ and $v \sim-7 \mathrm{~ms}^{-1}$. For $k<0$, the calculated apparent period is $-16.3 \leq 2 \pi / \omega \leq-4.5 \mathrm{~h}$ and for $k>0$, $2 \pi / \omega$ is comprised between 1.3 and $1.7 \mathrm{~h}$. Independently, the wave apparent period can be estimated from the time evolution of the temperature at this fixed location (Fig. 2a) which gives $|2 \pi / \omega| \sim 10 \mathrm{~h}$. Clearly, positive wavenumbers cannot explain the existing Doppler shift and therefore $k<0$. Furthermore, as the wave vector is aligned with the direction of propagation, $k<0$ also implies that $l<0$, thus the effective propagation angle is $\Theta=-173^{\circ}$ and the horizontal wave vector is directed towards west-south-west. For simplicity, the ray trajectory computed from this first estimation of the wave parameters, $k, l$ and $m$ (see Table 1) will be referred to as 'first guess ray' hereinafter. 

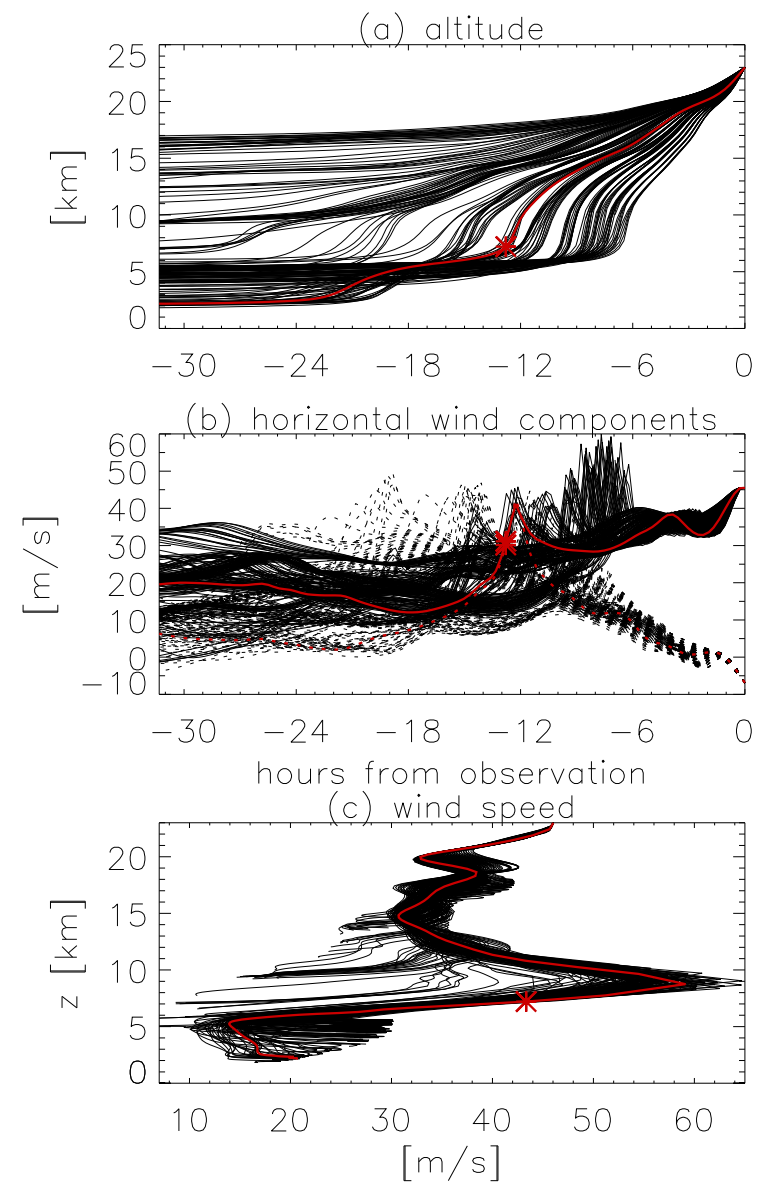
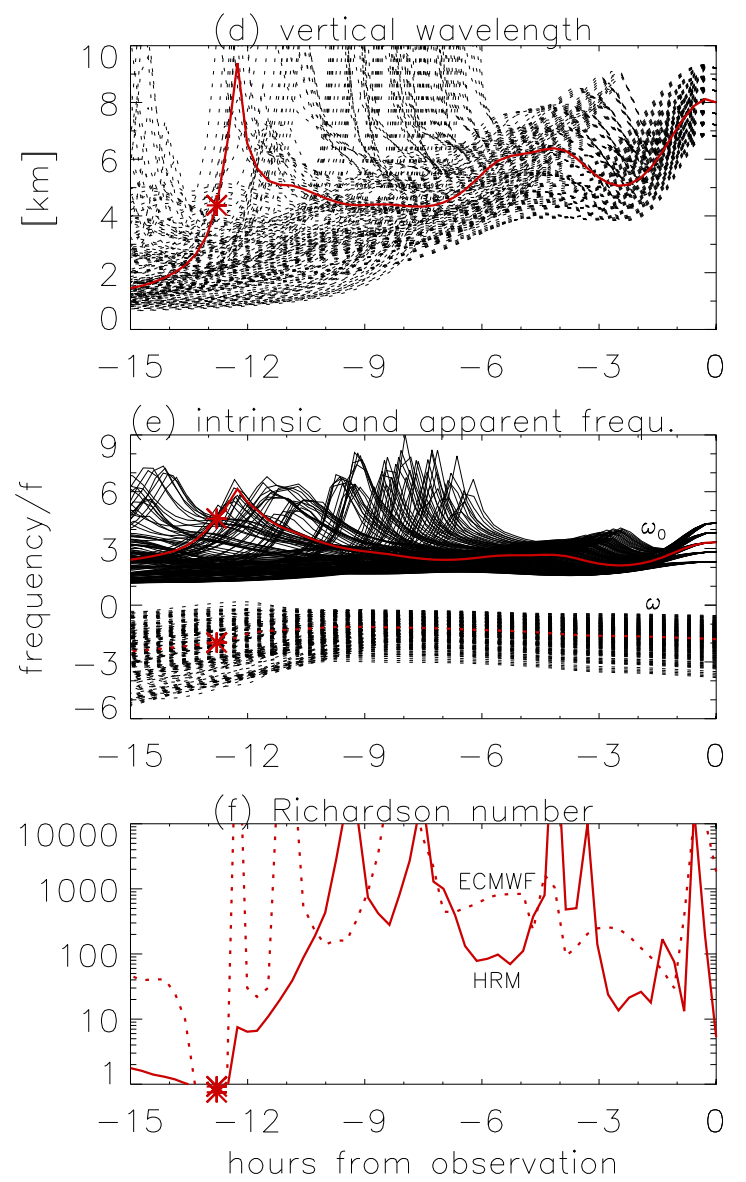

Fig. 10. Variables along the 175 backward ensemble ray trajectories: (a) altitude, (b) meridional (dashed) and zonal wind components from ECMWF analyses, (c) zonal and meridional (dashed) wavelengths, (d) vertical wavelength, (e) Richardson number from ECMWF (dashed) and HRM and (f) intrinsic and apparent (dashed) frequencies. The time of observation, $\left(t_{0}\right)$, is 14 January 07:30 UTC. The most likely trajectory is displayed in red. The stars show the supposed time of generation (see text).

Note that the apparent frequency determined from the temperature evolution at the location of cloud observation and estimated from the Doppler shift equation differ, but have the same order of magnitude. We will account for this discrepancy by starting an ensemble of rays, as noted above and described below. Further, the present wave parameters lie in the range of previously observed/simulated jet-induced gravity waves.

In order to take account of the errors which amplify along the ray simulations from the terminal conditions, we started an ensemble of ray trajectories, with initial conditions given by the uncertainties of the wave parameters, which we estimated generously. The wave parameters along with their estimated uncertainties are summarized in Table 1 . We allowed $\lambda_{z}$ to vary between 6.8 and $9.2 \mathrm{~km}$, in steps of $400 \mathrm{~m}$, and, $\Theta$ and $\omega_{0} / f$ as indicated in Table 1 , with each 5 possible values. In total, this yields 175 initial conditions. As a consequence, the horizontal wavelength varies between 241 and $684 \mathrm{~km}$.
The only parameters we assumed to be perfectly known are the time, height, longitude and latitude of the cloud observation. Because the ray trajectories were found to be little sensitive to their initial height within the range $z_{0}=23 \pm 1 \mathrm{~km}$, all trajectories were initiated at $23 \mathrm{~km}, 22.6^{\circ} \mathrm{W}$ and $77.3^{\circ} \mathrm{N}$ at 14 January, 07:30 UTC.

\subsubsection{Results}

The results are depicted in Fig. 10 for all 175 backward ray trajectories, with the 'first guess ray' indicated in red. The horizontal projection of the ray trajectories is shown in Fig. 13b. From the 175 ensemble members, there are 57 which remain in the stratosphere during the entire simulation (i.e. with $z$ always above $9 \mathrm{~km}$ ) They will not be considered in the following discussion. From all the trajectories coming from the troposphere, none started from ground levels above mountainous terrain. Thus, according to these ray trajectories, an orographic origin of 'wave DC8' can be ruled out. 
In the hours before the observation, as the wave packet ascends and its vertical wavelength increases, every ray encountered a caustic, indicated by an apparent change of sign in the action density (not shown). Nevertheless, Broutman (1986) shows that the ray-tracing equations can still produce valid results after the caustic, as also suggested by the smooth horizontal trace of the rays.

Note that the vertical wavelength of the 'first guess ray' (as of the other rays) rapidly increases from $\sim 5 \mathrm{~km}$ in the hours prior to observation (corresponding altitude of $20 \mathrm{~km}$ ). This is in nice quantitative agreement with the two levels of PSC in the lidar observations at about 18.5 and $23 \mathrm{~km}$ (see Fig. 1). This change in vertical wavelength might provide a part of the explanation of why no cloud is observed above $23 \mathrm{~km}$ : actually, if $\lambda_{z}$ remained constant $(5 \mathrm{~km})$, PSCs type I would be expected at $\sim 27 \mathrm{~km}$ height where the synoptic temperatures are very close to those at $\sim 19 \mathrm{~km}$ (Fig. 1), the first floor of PSCs; taking account that the NAT equilibrium temperature is $\sim 4 \mathrm{~K}$ lower at $27 \mathrm{~km}$ compared to $23 \mathrm{~km}$. The other part of the explanation is that the frost point is $\sim 3 \mathrm{~K}$ lower at $27 \mathrm{~km}$ as compared to the height of the ice cloud.

Between 6-12 $\mathrm{h}$ prior to the observation most of the ensemble's trajectories pass through the tropopause jet (which coincides with the increase in the vertical wavelength and intrinsic frequency). For the 'first guess ray', the wind speed at this moment exceeds $60 \mathrm{~ms}^{-1}$ (Fig. 10c) with a strong northerly component (Fig. 10b). (The mean and standard deviation of the wind velocity for the ensemble is $55 \pm 5 \mathrm{~ms}^{-1}$.) Shortly before crossing the jet, as this ray was already ascending, it was located in a positive vertical shear layer where the Richardson number, $R i$, becomes $<1$ in the ECMWF as well as in the HRM data fields (Fig. 10f). (For the ray ensemble the averaged minimum HRM Richardson number becomes $2.1 \pm 1.7$.) $R i$ is a dynamically significant stability and turbulence indicator. Shear instability can be expected where $R i$ is smaller than a certain threshold value. Calculated from gridded data fields, this threshold depends on resolution, and is taken typically as $R i_{c}=1$ in mesoscale models.

For the 'first guess ray', we identified its most probable location of wave generation (where $R i$ attains its minimum along the ray), accepting the possibility of wave generation by shear instability. This occurs at $54^{\circ} \mathrm{W}, 71^{\circ} \mathrm{N}$ and $t=-13 \mathrm{~h}$, or 13 January 18:30 UTC, near the $370 \mathrm{hPa}$ pressure level, or $300 \mathrm{~K}$ isentrope (see crosses in Figs. 10-13). This location coincides with the region of maximum vertical shear and low static stability (see Fig. 11), which is also a prerequisite for the onset of strong turbulence. Despite the dispersion of the ray trajectories, $85 \%$ of the ensemble members reaching the troposphere do attain their minimum in $R i$ in a very similar situation as the 'first guess ray', i.e. low static stability and large positive vertical shear, beneath the jet core. In this sense the 'first guess ray' is representative of the actual trajectory of the wave packet. The horizontal trace of the 'first guess ray' (only shown until the mini-

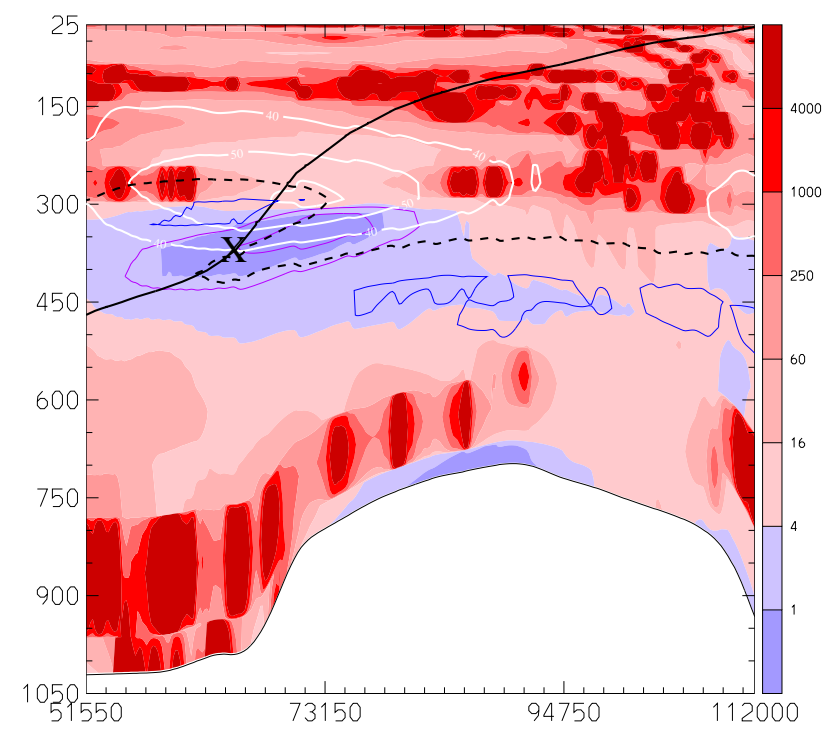

Fig. 11. Four-dimensional linear interpolation of the Richardson number (colors) from the HRM data along the ray-trajectory which is indicated by the black line as a function of pressure and time (seconds from 13 January 00:00 UTC). The cross denotes the minimum Richardson number along the trajectory and the possible location of wave generation (see text). The white contours denote the wind velocity (contours for 40, 50 and $60 \mathrm{~ms}^{-1}$ ); the violet contour show the positive vertical shear (contours for 12.5 and $\left.17.5 \cdot 10^{-3} \mathrm{~s}^{-1}\right)$; the blue contour tropospheric low static stability regions $\left(\mathrm{N}^{2}=1.25 \cdot 10^{-4} \mathrm{~s}^{-2}\right)$ and the dotted black curve shows the tropopause (defined by the $\mathrm{PV}=2$ pvu potential vorticity isosurface).

mum Richardson number in Fig. 13a) indicates that the wave has been generated on the northern side of the jet, characterized by cyclonic horizontal shear. O'Sullivan and Dunkerton (1995) and Thomas et al. (1999) also found wave emission in the jet exit region.

We now inspect the HRM atmosphere at the possible time and location of generation of 'wave DC8', according to the backward ray trajectory simulations. Figure 12 shows the divergence of the horizontal wind field multiplied by the air's density, in order to enhance the lower tropospheric wave signals, almost exactly along the ray trajectory (the horizontal trace of the vertical section is shown as the thick white line in Fig. 13a) at 13 January 2000, 21:00 UTC. The same sections for the two previous hours show similar patterns with less clarity. Beside signals due to the relaxation at the boundary of the mesoscale domain, Fig. 12 gives evidence for a GW propagating upwards and some indication of an other wave train propagating downwards that interferes with other lower tropospheric processes. Consistent with the backward ray trajectories, both waves look like being generated beneath the jet core. The wave propagating downwards has a much smaller vertical wavelength, while the one propagating upward exhibits characteristics that are in reasonable agreement with the results from the ray-trajectory calculations. 


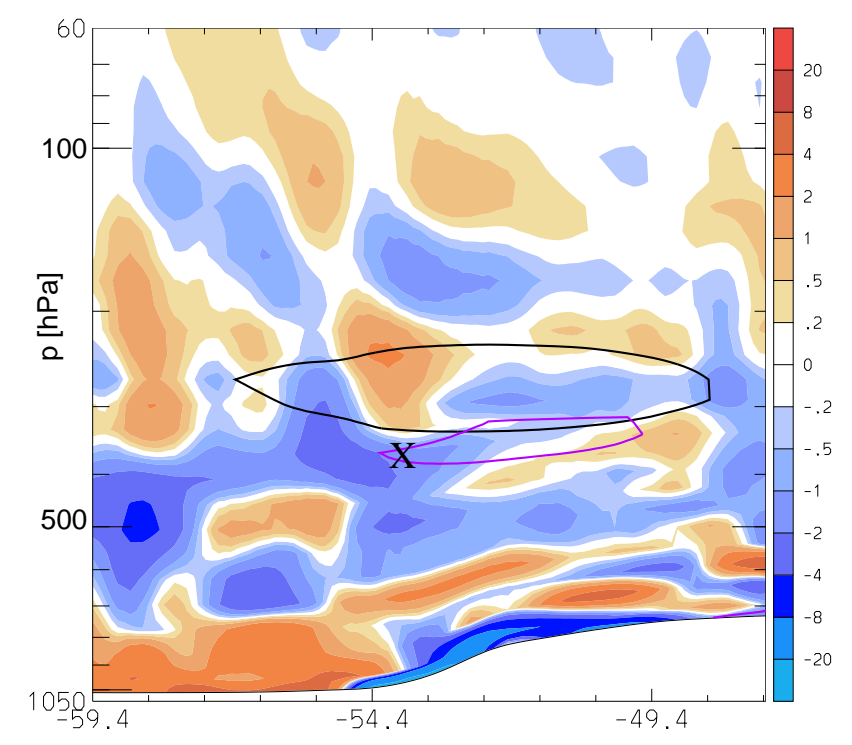

Fig. 12. Density weighted horizontal divergence $\left[10^{-5} \mathrm{~kg} \mathrm{~m}^{-3} \mathrm{~s}^{-1}\right]$ of the HRM wind field on the 13 January 2000 at 21:00 UTC. Black contour indicates the $50 \mathrm{~ms}^{-1}$ isotach and the purple contour shows values of $R i=1$. The cross is the location of the wave generation as inferred from the ray-tracing simulation. The horizontal trace of the section is shown in Fig. 13a.

Note further in Fig. 11 that the 'first guess ray' passes very close to a tropopause fold. Using a two-dimensional, isentropic primitive equation model, Gidel and Shapiro (1979) showed that two patches of turbulence can be associated with tropopause folds: one in the stratosphere above the jet core and one, stronger, situated in the troposphere below the jet axis. The fact that the ray hits an intense jet-stream, associated with a tropopause fold is a further piece of evidence that 'wave DC8' is emitted from a strong vertical shear layer.

\subsection{Potential wave emission diagnostics}

The ray-tracing analysis in the previous section showed the passage of the ray trajectory through a region with very small Richardson number and indicated the possibility of wave generation through shear instability. Here, we also like to adopt additional diagnostics for 'wave DC8' to investigate the degree of balance of the associated tropopause-level jet-streak. Following previous studies on unbalanced flow diagnostics (Zhang et al., 2000; Hertzog et al., 2001), the cross-stream Lagrangian Rossby number and the residual of the non-linear balance equation were calculated to analyze the likelyhood of geostrophic adjustment. In addition, the Richardson number is shown again as a proxy for the alternative process of shear instability. As the theoretical understanding of geostrophic adjustment and vertical shear instability is still limited, these diagnostics can only be regarded as (useful) proxies but they can not provide a final answer on (and a rigid criterion for) the GW generation.
First, Fig. 13a shows a horizontal view of $R i$ derived from HRM at the time and level of the supposed wave generation. In agreement with the discussion in the previous section, the westerly jet streak is associated with very low values $(R i<1)$ and it is within or close to this narrow band that many ray trajectories cross the tropopause level.

Second, the cross-stream Lagrangian Rossby number, $R o^{\perp}$, was computed with ECMWF data according to Plougonven et al. (2003):

$R o^{\perp}=\frac{\left|\mathbf{u}_{a g}^{\perp}\right|}{|\mathbf{u}|}$,

$\mathbf{u}_{a g}^{\perp}$ denoting the horizontal ageostrophic wind component perpendicular to the flow. Adjustment is diagnosed for large $R o^{\perp}$. The threshold value of $R o^{\perp}=0.35$ (suggested by Plougonven et al., 2003) is exceeded for most of our ray trajectories (see Fig. 13c): all of them pass closely to a region with large $R o^{\perp}$.

Finally the non-linear balance equation (NBE), derived from the full divergence tendency equation in the case where the advection term, the non-linear effects of divergence and the contributions of vertical motion gradients can be neglected, is given by

$2 \mathbf{J}(\mathbf{u}, \mathbf{v})-\beta u+f \zeta-\nabla^{2} \Phi=0$

where $J$ stays for the Jacobian, $\zeta$ is the relative vorticity and $\nabla^{2} \Phi$ stands for the horizontal Laplacian of the geopotential. Deviations from this balance condition, i.e. the residuum of Eq. (8), is also a measure for the flow's potential adjustment. Figure 13b shows this residual on the $370 \mathrm{hPa}$ surface computed with ECMWF analyses along with the full length of the ensemble rays. The region of maximum imbalance predicted by the NBE is located to the east of the region where the wave packets were presumably generated. The patch with largest deviations from non-linear balance corresponds quite well with the band of small $R i$ and the ensemble rays all travel through a region with substantial (although not maximum) diagnosed jet-stream imbalance.

Taken together, these brief diagnostics are supportive of our claim that 'wave DC8' is generated by either geostrophic adjustment or shear instability. A fully conclusive answer on which of these processes was responsible for the GW generation not possible based on our analyses. Regarding the scale of the identified inertio gravity wave, geostrophic adjustment seems more likely than instability.

\section{Potential for jet-induced GW in the SOLVE winter}

In order to estimate the likely frequency and potential importance of ice clouds generated by adjustment, we have applied the NBE (equation 8) diagnostics to the entire winter from the beginning of December 1999 to the end of March 2000. We have chosen a residual threshold of $4 \cdot 10^{-4} \mathrm{~s}^{-2}$ 

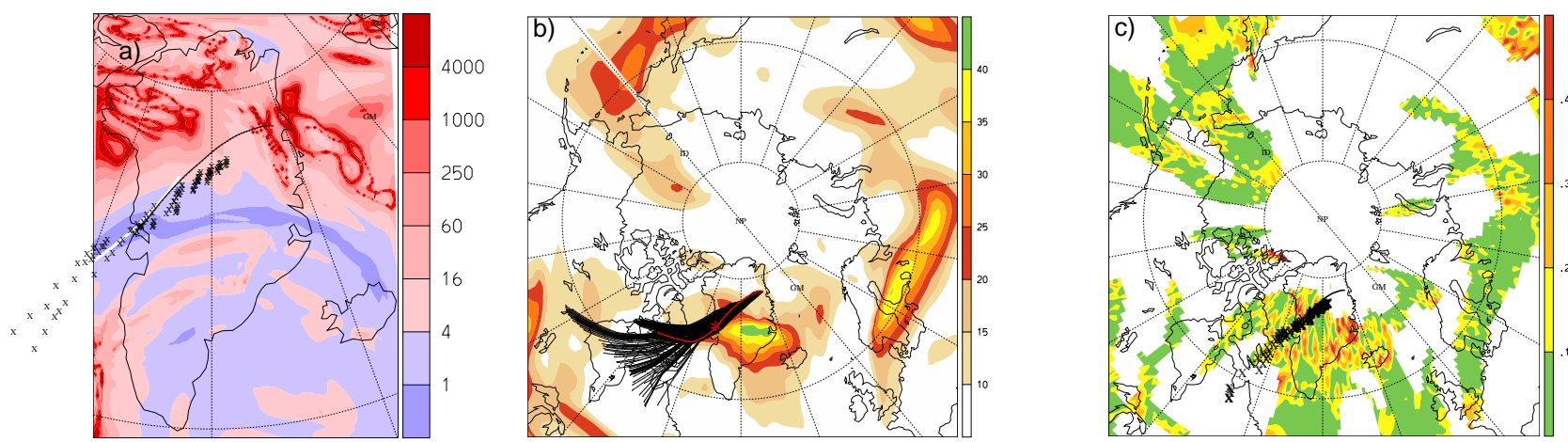

Fig. 13. Three diagnostics to identify the mechanism responsible for the GW emission near the upper-level jet stream (i.e. on $370 \mathrm{hPa}$ ): (a) the Richardson Number computed with HRM data at the presumed time of 'wave DC8' generation (19:00 UTC 13 January); (b) the residual from Eq. (8) (in units of $10^{-5} \mathrm{~s}^{-2}$ ), and (c) the cross-stream Lagrangian Rossby number $R o^{\perp}$ from Eq. (7) (only at grid points where $|\mathbf{u}|>20 \mathrm{~m} / \mathrm{s}$ to avoid spurious large values of $R o^{\perp}$ ). The two latter diagnostics (b, c) were computed with ECMWF data for 18:00 UTC 13 January. In panel (b) the ensemble rays are shown in full length, in red for the 'first guess ray' and in the other panels, the horizontal trace of the 'first guess ray' is indicated by the black line until its supposed generation and the crosses mark the locations where the ensemble ray trajectories cross the 370-hPa pressure surface. The bold white line in panel (a) indicates the location of the vertical cross section shown in Fig. 12.

and applied this threshold within the 100 to $500 \mathrm{hPa}$ vertical layer in the northern hemisphere $\left(20-90^{\circ} \mathrm{N}\right)$ to the 6 hourly ECMWF analyses.

The probability that for a given day and longitude (latitude), at least one time step and one model level within the height range exceeds the chosen threshold is shown in the upper (lower) panel of Fig. 14. It is shown that, mainly in January 2000, unbalance is also diagnosed at high latitudes. Note that the discussed case on 14 January is associated with a strong signal in this proxy climatology, as compared to other events at high latitudes during this winter. The computation indicates that jet induced GWs may be frequent, but mainly in the southernmost part of the Eurasian continent and the subtropical Pacific jet. In regions with the possibility for GWs to generate PSCs, say north of $60^{\circ} \mathrm{N}$, potential adjustment events are relatively rare $(\sim 3$ events during the considered period).

Generally the time evolution of the potential wave emission regions indicates eastward propagation with the same order of magnitude than the synoptic weather systems (Fig. 14, top). In the meridional direction (Fig. 14, bottom), it appears that several unstable regions describe an anticyclonic propagation, in agreement with the results of Knox (1996).

Better understanding of the physical processes that lead to the occurrence of vertical shear instabilities or adjustment would be strongly desirable and could lead to a better substantiated criterion for the identification of jet-induced GWs.

\section{Conclusions}

Using meteorological data from ECMWF analyses and mesoscale HRM hindcast simulations, we investigated the dynamical mechanisms that generated two vertically prop-

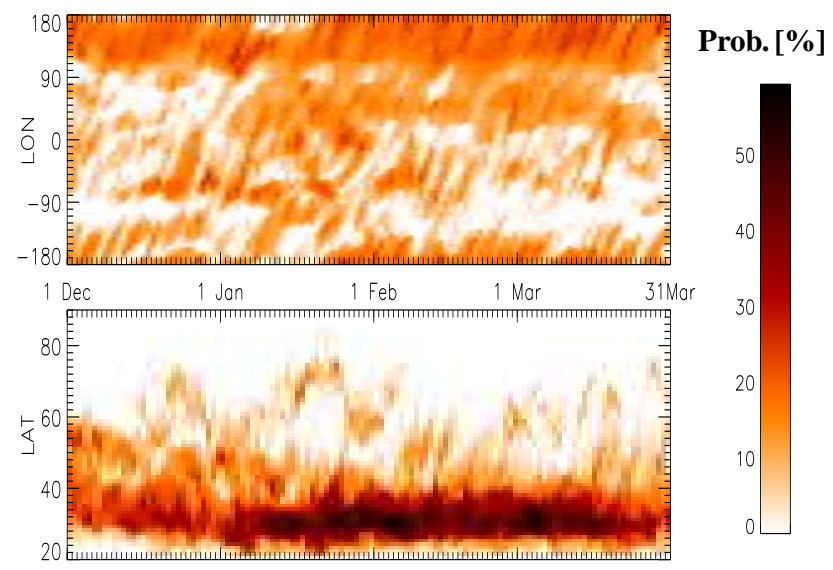

Fig. 14. Winter 1999/2000 climatology of potential geostrophic adjustment computed with the residual of the non-linear balance equation (Eq. 8) and ECMWF analyses fields. The probability depicted in the upper (lower) panel is that at least on one model level in the $500-100 \mathrm{hPa}$ range, the residual of the NBE exceeds $4 \cdot 10^{-4} \mathrm{~s}^{-2}$ for all latitudes (longitudes) and every ECMWF output within a given day.

agating gravity waves. 'Wave ER2' was undoubtfully generated by the orography and we have given multiple evidence that 'wave DC8' was generated near an intense uppertropospheric jet streak, potentially by spontaneous adjustment and/or vertical shear instability. In particular, we detected that the tropopause-level and surface synoptic features were very similar to the 13 jet-induced GW cases reviewed in Uccellini and Koch (1987): a surface low upstream of the wave activity with an associated northeast-southwest oriented distinct frontal boundary and wave generation at the exit region of an intense jet streak. Furthermore, the most 
plausible location of wave production was in the very vicinity of a tropopause fold associated with the strong jet.

In the HRM simulation, the simulated wave does account for the $8 \mathrm{~K}$ mesoscale cooling. It remains an open question whether in reality small-scale non-hydrostatic gravity waves (that can not be captured by the HRM hydrostatic model simulation) further modify the temperature field and the internal cloud structure. The lidar signal indicates that mountain waves with a horizontal scale of $\sim 15 \mathrm{~km}$ propagate until the cloud location. Therefore, the ice cloud could be the result of superimposition and/or interaction of a broader spectrum of atmospheric waves than finally simulated.

Still, the mesoscale model HRM was found to be a suited model for the simulation of vertically propagating waves which, in the present study, applies for two different wave generation mechanisms. In particular, the model simulation captured very well the amplitude and location of the cold spot with $T<T_{\text {ice }}$. Sensitivity experiments (see Appendix) revealed however, that the model results are sensitive to the horizontal diffusion and initialization time.

In line with the recent studies of Hitchman et al. (2003) and Shibata et al. (2003) this study indicates that mesoscale PSCs can be induced not only by orographically triggered GWs but also via an alternative mechanism that is related to the rapid evolution of intense and curved jet streams near the tropopause level. It remains for further work to quantify the relevance of the two mechanisms. Our preliminary attempt to count the potential geostrophic adjustment events in the polar regions during one winter indicates that they occur only sporadically.

\section{Appendix: Sensitive dependencies to model parameters}

Eleven numerical sensitivity experiments have been conducted to test the dependencies of the HRM simulations to several model parameters and processes. Compared to the original simulation discussed in the paper (in the following called control run), they were undertaken changing one parameter each time. These comprise changes of the horizontal and vertical resolution, variations in horizontal diffusion, modifications in the initialization time and inclusion or not of physical parametrizations. Table 2 summarizes the eleven experiments along with the minimum modeled temperatures at the locations of the observed waves. These experiments are discussed hereafter.

Initialization The choice of the initialization time of a simulation is subtle when comparing with observations at a particular time. The longer the run, the more the mesoscale model will develop its own dynamics and might drift away from the driving analyses. On the other hand, too late a starting time of the simulation may prevent the mesoscale features (as GWs) to develop and fully propagate. Four runs with initialization prior to the initialization of the control run two runs with initialization after the 13 January 2000,
Table 2. Summary of the numerical experiments conducted with the mesoscale model HRM. $T_{\min }^{\mathrm{ICE}}$ stays for the Temperature at the time and location of maximum observed backscatter ratio and on the $25.3 \mathrm{hPa}$ level, $T_{\min }^{\mathrm{DC} 8}$ is the minimum temperature at the same location at any height. and $T_{\min }^{\mathrm{ER} 2}$ is the minimum temperature where the ER-2 observed a local minimum in the temperature.

\begin{tabular}{lcccc}
\hline Simulation & $T_{\min }^{\mathrm{ICE}}$ & $T_{\min }^{\mathrm{DC} 8}$ & $p\left(T_{\min }^{\mathrm{DC}}\right)$ & $T_{\min }^{\mathrm{ER} 2}$ \\
\hline Initial. 12 Jan. 12:00 UTC & -88.6 & -88.9 & 23.8 & -81.8 \\
Initial. 12 Jan. 18:00 UTC & -87.3 & -87.4 & 26.4 & -82.6 \\
Initial. 13 Jan. 00:00 UTC & -88.5 & -88.9 & 23.8 & -83.6 \\
Initial. 13 Jan. 06:00 UTC & -89.6 & -89.7 & 23.8 & -84.0 \\
control run & -91.2 & -91.3 & 23.8 & -82.6 \\
Initial. 13 Jan. 18:00 UTC & -88.2 & -88.3 & 21.4 & -83.1 \\
Initial. 14 Jan. 00:00 UTC & -83.9 & -84.9 & 19.3 & -82.0 \\
30 vertical levels & -85.7 & -87.3 & 15.6 & -83.8 \\
double mesh-widths & -93.0 & -93.7 & 21.4 & -83.6 \\
10x diffusion & -87.7 & -87.8 & 21.4 & -84.0 \\
moist physics & -89.8 & -89.8 & 21.4 & -84.0 \\
conv no rad & -90.9 & -91.0 & 23.8 & -84.1 \\
\hline
\end{tabular}

12:00 UTC have been performed to evaluate this significant sensitivity (see Table 2 ).

For the temperature at the location of the cloud observed by the DC-8, the minimum is achieved with the control simulation. The more the simulation is initialized earlier or later, the more the amplitude of the wave decreases and the higher becomes the minimum mesoscale temperature. Note also the slight vertical shift in the height of minimum temperature at this location as the initialization moves away from the control run. For the experiment started on 14 January 00:00 UTC, the DC8 wave structure becomes hardly identifiable (e.g. in vertical sections similar to the ones shown in Figs. 1 and 7) which expresses either that the onset of the wave was missed or that the GW had no time to propagate to the flight path. According the ray-tracing simulations the former is more likely the case.

A similar behavior, even if less marked is found for the minimum temperature associated with 'wave ER2'. The simulation which produces the minimum temperature was initialized six hours before the control run.

Resolution In order to test the impact of vertical resolution, the number of vertical levels was reduced by a factor of two, the model top kept unchanged. 'Wave DC8' appears to be emitted properly but dissipates prior to reach the cloud altitude. There, an upward shifted temperature minimum exists but the wave structure cannot be recognized any longer. This is in good agreement with the ray tracing model (see Fig. 10b) which indicated that at the moment of emission the vertical wavelength was smaller than at the moment of observation. The effect of the vertical resolution on the 'wave ER2' with larger vertical wavelength is negligible.

Repeating the control run with doubled horizontal mesh width, roughly extinguishes 'wave ER2' as revealed by an 
equivalent to Fig. 7. However this simulation delivers the absolute minimum temperature associated with 'wave DC8' of all simulations.

An increase in horizontal and/or vertical resolution was not undertaken due to computational limitations. Furthermore, additional reduction of the horizontal mesh width makes no sense for a hydrostatic model.

Diffusion In this experiment, the horizontal diffusion coefficients were increased by an order of magnitude. The effect on 'wave DC8' is dramatic as its temperature minimum increases by $4 \mathrm{~K}$ while the effect on the minimum temperature associated with 'wave ER2' was astonishingly a cooling of $1.5 \mathrm{~K}$. A plausible explanation is that the wave encounters less destructive interference with other short wavelengths waves, since these are filtered by the strong diffusion as seen in an equivalent of Fig. 7. O'Sullivan and Dunkerton (1995) established that inertio GW are primarily sensitive to horizontal hyperdiffusion. Here, not only the amplitude of "wave DC8' was reduced but also its vertical wavelength

Physical parametrizations The inclusion of convection or the exclusion of the radiation scheme in the simulation gave strikingly similar wave characteristics. These processes have no influence on the generation and propagation of GW up to the stratosphere at least for the present setup. This is not the case for the inclusion of moisture: the diabatic effects associated with the evaporation and condensation of water impinged on the simulated temperatures.

Acknowledgements. SB was partially supported through the EC-project THESEO-2000/EuroSOLVE (under contract BBW 99.0218-2, EVK2-CT-1999-00047) and through an ETHZ-internal research project.

We thank the ECMWF, MeteoSwiss, and the GSFC DAAC for providing access to the meteorological data. We are also very grateful to the ETHZ Cray staff for accommodating the large computational resources needed for the HRM simulations. Acknowledged are H. Davies, B. Luo and S. Fueglistaler for the fruitful discussions. We proudly and warmly thank the reviewers, M. McIntyre and A. Dörnbrack, as well as the editor, P. Haynes, for their insightful contributions, which improved noticeably the present manuscript.

Edited by: P. Haynes

\section{References}

Andrews, D. G., Holton, J. R., and Leovy, C. B.: Middle atmosphere dynamics, Academic Press, San Diego, 489, 1987.

Bougeault, P.: A non-reflective upper boundary condition for limited area grid, Mon. Wea. Rev., 111, 420-429, 1983.

Bretherton, F. P.: Momentum transport by gravity waves, Q. J. R. Meteorol. Soc., 95, 213-243, 1969.

Broutman, D.: On internal wave caustics, J. Phys. Oceanogr., 16, 1625-1635, 1986.

Cariolle, D., Muller, S., Cayla, F., and McCoirmick, M. P.: Mountain waves, polar stratospheric clouds, and the ozone depletion over Antarctica, J. Geophys. Res., 94 (D9), 11 233-11 240, 1989.
Carslaw, K. S., Wirth, M., Tsias, A., Luo, B. P., Dörnbrack, A., Leutbecher, M., Volkert, H., Renger, W., Bacmeister, J. T., Reimer, E., and Peter, T.: Increased stratospheric ozone depletion due to mountain-induced atmospheric waves, Nature, 391, 675-678, 1998.

Chan, K. R., Pfister, L., Bui, T. P., Bowen, S. W., Dean-Day, J., Gary, B. L., Fahey, D. W., Kelly, K. K., Webster, C. R., and May, R. D.: A case study of the mountain lee wave event of January 6, 1992, Geophys. Res. Lett., 20, 2551-2554, 1993.

Dörnbrack, A., Leutbecher, M., Kivi, R., and Kyrö, E.: Mountain wave-induced record low stratospheric temperatures above northern Scandinavia, Tellus, 51A, 951-963, 1999.

Dörnbrack, A., Birner, T., Fix, A., Flentje, H., Meister, A., Schmid, H., Browell, E. V., and Mahoney, M. J.: Evidence for inertia-gravity waves forming polar stratospheric clouds over Scandinavia, J. Geophys. Res., 107 (D20), 8287, doi:10.1029/2001JD000452, 2002.

European Center for Medium-Range Weather Forecasts: Newsletter, 83, Reading, United Kingdom, 1999.

Frei, C., Christensen, J. H., Déqué, M., Jacob, D., Jones, R. G., and Vidale, P. L.: Daily precipitation statistics in regional climate models: Evaluation and intercomparison for the European Alps, J. Geophys. Res., 108 (D3), 4124, doi:10.1029/2002JD002287, 2003.

Fritts, D. C. and Nastrom, G. D.: Sources of mesoscale variability of gravity waves, Part II: frontal, convective and jet stream excitation, J. Atmos. Sci., 49, 111-127, 1992.

Fueglistaler, S., Buss, S., Luo, B. P., Wernli, H., Flentje, H., Hostettler, C. A., Poole, L. R., Carslaw, K. S., and Peter, Th.: Detailed modeling of mountain wave PSCs, Atmos. Chem. Phys., 3, 697$712,2003$.

Gidel, L. T. and Shapiro, M. A.: The role of clear air turbulence in the production of potential vorticity in the vicinity of upper tropospheric jet stream-frontal systems, J. Atmos. Sci., 36, 2125 2138, 1979.

Gossard, E. E. and Hooke, W. H.: Waves in the atmosphere, Developments in atmospheric science, Elsevier Scientific Publishing Co., Amsterdam, 456, 1975.

Hanson, D. and Mauersberger, K.: Laboratory studies of the nitric acid trihydrate: implications for the south polar stratosphere, Geophys. Res. Lett., 15, 855-858, 1988.

Hertzog, A., Souprayen, C., and Hauchecorne, A.: Observation and backward trajectory of an inertio-gravity wave in the lower stratosphere, Ann. Geophys., 19, 1141-1155, 2001.

Herzog, H. J.: Testing a radiative upper boundary condition in a nonlinear model with hybrid vertical coordinate, Meteorol. Atmos. Phys., 55, 185-204, 1995.

Hitchman, M. H., Buker, M. L., Tripoli, G. J., Browell, E. V., Grant, W. B., McGee, T. J., and Burris, J. F.: Nonorographic generation of Arctic polar stratospheric clouds during December 1999 J. Geophys. Res., 108 (D5), 8325, doi:10.1029/2001JD001034, 2003.

Jones, W. L.: Ray tracing for internal gravity waves, J. Geophys. Res., 74 (8), 2028-2033, 1969.

Klemp, J. B. and Durran, D. R.: An upper boundary condition permitting internal gravity wave radiation in numerical mesoscale models, Mon. Wea. Rev., 111, 430-444, 1983.

Knox, J. A.: Possible mechanisms of clear-air turbulence in strongly anticyclonic flows, Mon. Wea. Rev., 125, 1251-1259, 1997. 
Koop, T., Luo, B. P., Tsias, A., and Peter, T.: Water activity as the determinant for homogeneous ice nucleation in aqueous solutions, Nature, 406, 611-614, 2000.

Leutbecher, M. and Volkert, H.: The propagation of mountain waves into the stratosphere: quantitative evaluation of three dimensional simulations, J. Atmos. Sci., 57, 3090-3108, 2000.

Lighthill, M. J.: Waves in fluids, Cambridge University Press, 504, 1978.

Luo, B. P., Voigt, C., Fueglistaler, S., and Peter, Th.: Extreme NAT supersaturations in mountain wave ice PSCs - a clue to NAT formation, J. Geophys. Res., 108 (D15), 4441, doi:10.1029/2002JD003104, 2003.

Lüthi, S.:Idealisierte Gebirgsüberströmung in einem operationellen numerischen Modell, Diploma Thesis, ETH Zürich, 141, 1994.

Lüthi, D., Cress, A., Davies, H. C., Frei, C., and Schär, C.: Interannual variability and regional climate simulations, Theor. Appl. Climatol., 53, 185-209, 1996.

McIntyre, M. E.: Balanced Flow, Encyclopedia of Atmospheric Sciences, edited by Holton, J. R., Pyle, J. A., and Curry, J. A., Academic Press, 680-685, 2003.

Majewski, D.: The Europa-Model of the DWD, ECMWF seminar on numerical methods in atmospheric science, 147-191, 1991.

Marks, C. J. and Eckermann, S. D.: A three-dimensional nonhydrostatic ray-tracing model for gravity waves: Formulation and preliminary results for the middle atmosphere, J. Atmos. Sci., 52, 1959-1984, 1995.

O'Sullivan, D. and Dunkerton, T. J.: Generation of inertio-gravity waves in a simulated life cycle of baroclinic instability, J. Atmos. Sci., 52, 3695-3716, 1995.

Pavelin, E., Whiteway, J. A., and Vaughan, G.: Observation of gravity wave generation and breaking in the lowermost stratosphere, J. Geophys. Res., 106, 5173-5179, 2001.

Peters, D., Hoffmann, P., and Alpers, M.: On the appearance of inertio-gravity waves on the north-easterly side of an anticyclone, Meteor. Zeitschrift, 12, 25-35, 2003.

Plougonven, R. and Teitelbaum, H.: Comparison of a largescale inertia-gravity wave as seen in the ECMWF analyses and from radiosondes, Geophys. Res. Lett., 30 (18), 1954, doi:10.1029/2003GL017716, 2003.

Plougonven, R., Teitelbaum, H., and Zeitlin, V.: Inertia gravity wave generation by the tropospheric midlatitude jet as given by the Fronts and Atlantic Storm-Track Experiment radio soundings, J. Geophys. Res., 108 (D21), 4686, doi:10.1029/2003JD003535, 2003.

Rabier, F., Järvinen, H., Klinker, E., Nahfouof, J.-F., and Simmons, A.: The ECMWF operational implementation of four dimensional variation assimilation, Part I: Experimental results with simplified physics, Q. J. R. Meteorol. Soc., 126, 1143-1170, 2000.

Schwierz C.: Interactions of Greenland-scale orography and extratropical synoptic-scale flow, Diss. ETH No. 4356, 2001.

Scinocca, J. F. and Ford, R.: The nonlinear forcing of large-scale internal gravity waves by stratified shear instability, J. Atmos. Sci., 57, 653-672, 2000.

Scott, S. G., Chan, K. R., Bowen, S. W., and Bui, T. P.: The Meteorological Measurement System on the NASA ER-2 aircraft, J. Atmos. Oceanic Technol., 7, 525-540, 1990.

Shibata, T., Sato, K., Kobayashi, H., Yabuki, M., and Shiobara, M.: Antarctic polar stratospheric clouds under temperature perturbations by nonorographic inertia gravity waves observed by micropulse lidar at Suowa station, J. Geophys. Res., 108 (D3), 4105, doi:10.1029/2002JD002713, 2003.

Sutherland, B. R. and Peltier, W. R.: Internal gravity-wave emission into the middle atmosphere from a model tropospheric jet, J. Atmos. Sci., 52, 3214-3235, 1995.

Thomas, L., Worthington, R. M., and McDonald, A. J.: Inertiagravity waves in the troposphere and lower stratosphere associated with a jet stream exit region, Ann. Geophys., 17, 115-121, 1999.

Uccellini, L. W. and Koch, S. E.: The synoptic setting and possible energy sources for mesoscale wave disturbances, Mon. Wea. Rev., 115, 721-729, 1987.

Wernli, H. and Davies, H. C.: A Lagrangian-based analysis of extratropical cyclones, I: The method and some applications, Q. J. R. Meteorol. Soc., 123, 467-489, 1997.

Whiteway, J. A. and Duck, T. J.: Enhanced Arctic stratospheric gravity wave activity above a tropospheric jet, Geophys. Res. Let., 26, 2453-2456, 1999.

Zhang, F., Koch, S. E., Davis, C. A., and Kaplan, M. L.: A survey of unbalanced flow diagnostics and their application, Adv. Atmos. Sci., 17, 165-183, 2000. 